\title{
Reactive Astrocytes: Critical Players in the Development of Chronic Pain
}

\author{
James Tang, Mercedes Bair and Giannina Descalzi * \\ Department of Biomedical Sciences, Ontario Veterinary College, University of Guelph, Guelph, ON, Canada
}

Chronic pain is associated with long term plasticity of nociceptive pathways in the central nervous system. Astrocytes can profoundly affect synaptic function and increasing evidence has highlighted how altered astrocyte activity may contribute to the pathogenesis of chronic pain. In response to injury, astrocytes undergo a shift in form and function known as reactive astrogliosis, which affects their release of cytokines and gliotransmitters. These neuromodulatory substances have been implicated in driving the persistent changes in central nociceptive activity. Astrocytes also release lactate which neurons can use to produce energy during synaptic plasticity. Furthermore, recent research has provided insight into lactate's emerging role as a signaling molecule in the central nervous system, which may be involved in directly modulating neuronal and astrocytic activity. In this review, we present evidence for the involvement of astrocyte-derived tumor necrosis factor alpha in pain-associated plasticity, in addition to research suggesting the potential involvement of gliotransmitters D-serine and adenosine-5'-triphosphate. We also discuss work implicating astrocyte-neuron

OPEN ACCESS

Edited by:

Kenji Hashimoto,

Chiba University, Japan

Reviewed by:

Peter llles,

Leipzig University, Germany

Koichi Iwata,

Nihon University, Japan

*Correspondence:

Giannina Descalzi gdescalz@uoguelph.ca

Specialty section:

This article was submitted to

Molecular Psychiatry,

a section of the journal

Frontiers in Psychiatry

Received: 18 March 2021 Accepted: 03 May 2021

Published: 28 May 2021

Citation:

Tang J, Bair M and Descalzi G (2021) Reactive Astrocytes: Critical Players in the Development of Chronic Pain. Front. Psychiatry 12:682056. doi: 10.3389/fpsyt.2021.682056 metabolic coupling, and the possible role of lactate, which has been sparsely studied in the context of chronic pain, in supporting pathological changes in central nociceptive activity.

Keywords: chronic pain, plasticity, astrocytes, cytokine, TNF $\alpha$, lactate, gliotransmission

\section{INTRODUCTION}

Chronic pain is associated with long lasting structural and functional reorganization of nociceptive circuits in the spinal cord and brain $(1,2)$. Historically considered supportive cells, mounting evidence indicates that astrocytes are dynamic players in neuroplasticity, and astrocytes have become increasingly recognized as active players in synaptic changes associated with chronic pain states. Pathologies of the central nervous system (CNS) often involve reactive astrogliosis, a process whereby astrocytes undergo a shift in morphology and function $(3,4)$. Reactive astrogliosis is associated with astrocyte hypertrophy, upregulated expression of glial fibrillary acidic protein (GFAP), and altered gene expression (5). Repeatedly, studies utilizing various rodent models of chronic pain show that GFAP is upregulated in the spinal cord (6-11) and brain areas involved in processing the sensory and affective components of pain, including the anterior cingulate cortex (ACC) (12-16), somatosensory cortex (17), amygdala $(18,19)$, thalamus $(20)$, and ventrolateral periaqueductal gray (21-24). Notably, inhibiting astrocyte activity in the spinal cord (25-27) and primary somatosensory cortex (17) has been shown to reduce pain hypersensitivity. Chronic pain is also often associated with depression and elevated anxiety, and astrocyte inhibitors administered into the ACC have been shown to alleviate anxiety and depression-related symptoms in rodents $(13,15)$. Moreover, recent research has provided evidence for glial activation in the spinal cord and brain of patients with various chronic pain syndromes (28-31), and enhanced astrocyte activation 
has been observed in the spinal dorsal horn of HIV patients with chronic pain (32). Given the consistent theme of astrocyte activation, recent research has focused on investigating the role of reactive astrocytes in the pathogenesis of chronic pain. This brief review will cover recent literature identifying astrocytederived cytokines, gliotransmission, and altered astrocyteneuron metabolic coupling as potential contributors to the persistently altered synaptic activity observed in chronic pain states.

\section{CYTOKINES}

Cytokines are important regulators of inflammatory responses, and the activity of several pro-inflammatory and antiinflammatory cytokines within the peripheral and central nervous systems (PNS and CNS, respectively) have been found to correspond with chronic pain states (33). Astrocytes and microglia release and respond to cytokines and play a significant role in immune responses of the CNS. Substantial research has uncovered microglia-mediated cytokine activity in chronic pain states. For example, spinal microglia are activated in inflammatory and neuropathic pain models $(34,35)$, and are associated with the production of pro-inflammatory cytokines such as tumor necrosis factor alpha (TNF $\alpha)$, interleukin-1 beta (IL-1 $\beta)$, IL-6, and interferon gamma (IFN $\gamma)(34,36)$. Additionally, specific microglia inhibitors can attenuate painrelated behaviors while significantly inhibiting the upregulation of pro-inflammatory cytokines $(37,38)$. But while microglia contribute to the pro-inflammatory phenotype in concert with astrocytic activity, the present review will focus specifically on astrocytes [for excellent reviews regarding microglia in chronic pain, see references (39) and (40)]. Numerous in-vitro observations show that stimuli ranging from lipopolysaccharide, metabolic and mechanical stress, and neurotropic viruses, stimulate astrocytic production and release of cytokines (41-45). These include, but are not limited to, TNF $\alpha$, IL-1 $\alpha$, IL-1 $\beta$, IL-6, IFN $\alpha$, IFN- $\beta$, and IFN $\gamma$ (41-45). Work done in post-mortem tissue from chronic pain patients has associated spinal astrocyte activation with production of inflammatory cytokines such as IL-1 $\beta$ and TNF $\alpha$ (32), while an in vivo pain model has shown that inhibiting astrocytes with the toxin $\mathrm{L}-\alpha$-aminoadipate can reduce IL- $1 \beta$ expression and mechanical allodynia (46). Notably, elevated levels of pro-inflammatory cytokines have been observed in the blood and cerebral spinal fluid of patients with chronic pain, and have been shown to positively correlate with subjective ratings of pain intensity $(47,48)$.

\section{TNF $\alpha$ DIRECTLY MODULATES NOCICEPTIVE NEURONAL ACTIVITY}

TNF $\alpha$ 's pathogenicity is well-documented in the peripheral nervous system. Direct injection of TNF $\alpha$ into the sciatic nerve or acute application to the L4 dorsal root ganglion (DRG) induces signs of mechanical allodynia and thermal hyperalgesia, however symptoms appear to be short-lived with recovery occurring within a couple days (49-51). Chronic application of a pad soaked in TNFa to the L5 nerve root or chronic perfusion of the DRG resulted in symptoms persisting beyond 7 days $(52,53)$, suggesting a requirement for extended exposure in the periphery to initiate long lasting pain. TNF $\alpha$ perfusion at the DRG is also able to enhance pain symptoms associated with compression of the DRG (53).

In the central nervous system, chronic pain induction elevates TNF $\alpha$ levels in the dorsal horn of the spinal cord, which either coincide with or are temporally close to the onset of mechanical and thermal hypersensitivity (54-58). In the brain, the time course of TNF $\alpha$ elevations in chronic pain models varies between different regions. For example, TNF $\alpha$ levels are elevated in the locus coeruleus prior to the onset of chronic constriction injury induced thermal hyperalgesia, while rises and falls in hippocampal $\mathrm{TNF} \alpha$ approximately correspond to symptom onset and dissipation, respectively $(58,59)$. In the ACC, TNFa expression increases shortly after the onset of spared nerve injury-induced mechanical allodynia (60).

Research has shown that TNF $\alpha$ is able to modulate synaptic activity by acting directly on neurons via tumor necrosis factor receptor 1 (TNFR1) (61, 62) (Figure 1). Notably, astrocyte derived TNF $\alpha$ increases AMPA receptor and decreases $\mathrm{GABA}_{\mathrm{A}}$ receptor surface expression in cultured hippocampal neurons leading to increases in frequency and amplitude of mini excitatory postsynaptic currents (mEPSCs), and decreases in amplitude of mini inhibitory postsynaptic currents (61-63). Similar observations have been made in slices from the ACC, where TNF $\alpha$ increases the amplitude of evoked EPSCs and mEPSC frequency (64). TNF $\alpha$ can also increase the probability of presynaptic neurotransmitter release (64), through mechanisms that may involve the cation channel TRPV1 $(65,66)$. This TNF $\alpha$ mediated increase in neuronal excitability may participate in homeostatic synaptic scaling resulting from depressed synaptic activity, a process which is reliant on astrocytic rather than neuronal production of TNFa (67). Later work in neuronal cultures argues that rather than simply shifting neurons toward increased excitation, TNF $\alpha$ may act to permit rather than drive synaptic plasticity (68). Indeed, bidirectional effects have been observed, whereby high concentrations of TNF $\alpha$ (1 $\mathrm{ug} / \mathrm{mL}$ ) has been shown to impair the induction of long-term potentiation (LTP), while low concentrations $(1 \mathrm{ng} / \mathrm{mL}$ ) facilitate LTP (69). Studies assessing cytokine concentrations in chronic pain patients have found TNF $\alpha$ levels ranging from a few $\mathrm{pg} / \mathrm{mL}$ or less in cerebrospinal fluid $(47,70)$, up to approximately $50 \mathrm{pg} / \mathrm{mL}$ in blood $(48,71,72)$. As these concentrations are far below the level at which TNF $\alpha$ was found to impair LTP, $\mathrm{TNF} \alpha$ release from reactive astrocytes may be more likely to instead facilitate synaptic potentiation. Accordingly, animal models of chronic inflammatory pain have also shown persistent 1-3 pg/mg increases in TNF $\alpha$ above baseline in the ACC and basolateral amygdala, which were associated with enhanced synaptic transmission in these regions, suggesting a possible role of astrocyte-derived TNF $\alpha$ in pain-induced hyperactivity $(64,73)$. 


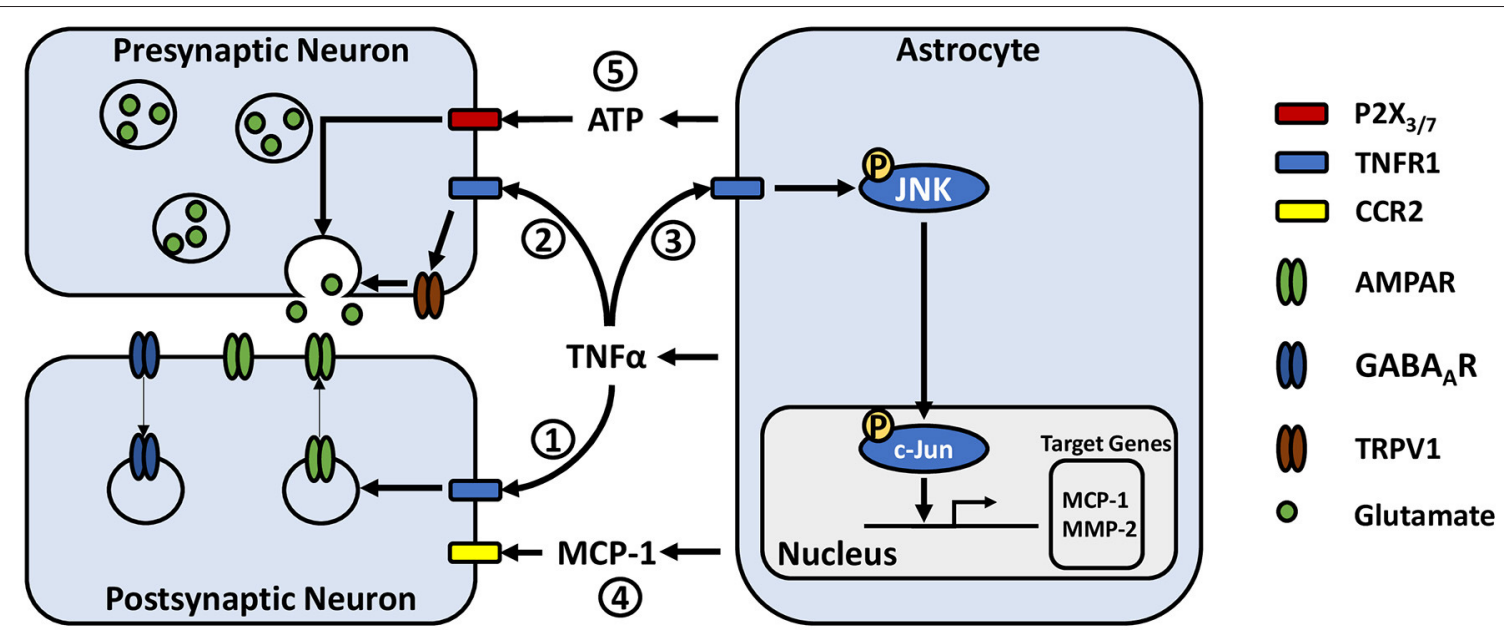

FIGURE 1 | Potential astrocyte-neuron signaling pathways in modulating pain-related synaptic transmission. (1) TNF $\alpha$ acts on neuronal TNFR1 resulting in rapid trafficking of GluR2-lacking AMPA receptors to the postsynaptic membrane and internalization of postsynaptic GABA receptors. (2) TNF $\alpha$ increases presynaptic glutamate release, potentially by activating or increasing the expression of transient receptor potential subtype V1. (3) TNF $\alpha$ acts on astrocytic TNFR1, inducing phosphorylation of JNK. JNK phosphorylates c-Jun, which dimerizes with c-Fos to form the AP-1 transcription factor, leading to transcription of target genes such as MCP-1 and MMP-2. (4) MCP-1 is released from astrocytes where it can act on neurons via CCR2, modulating their excitability. (5) ATP released from astrocytes may act on pre-synaptic neuronal $\mathrm{P} 2 \mathrm{X}_{3}$ and $\mathrm{P} 2 \mathrm{X}_{7}$ receptors, stimulating glutamate release.

\section{TNF $\alpha$ ACTIVATES THE JNK SIGNALING PATHWAY IN ASTROCYTES}

Astrocyte-microglia crosstalk via cytokine signaling is emerging as an important mechanism in the development of chronic pain. Microglial release of IL-18 has been associated with astrocyte activation, while astrocytic CXCL12 has been reported to influence microglia, contributing to the development of mechanical allodynia in neuropathic and migraine pain models (74-76). Like neurons, both astrocytes and microglia express TNFR1 $(77,78)$ and are able to respond to $\mathrm{TNF} \alpha$ (Figure 1). Recent cell culture studies have reported that activated microglia may induce reactive astrogliosis through the release of TNF $\alpha$ amongst other cytokines $(79,80)$. Additionally, astrocytic TNF $\alpha$ has been reported to exert autocrine effects in culture (81). A series of experiments by Yong Jing Gao and colleagues found evidence for a signaling pathway by which $\mathrm{TNF} \alpha-$ induced astrocyte activation could contribute to persistent pain hypersensitivity. They showed in primary astrocyte cultures that TNF $\alpha$ induces transient TNFR1-dependent phosphorylation of c-Jun N-terminal kinase 1 (pJNK1) (82), a mitogen-activated protein kinase (MAPK). pJNK1 phosphorylates and activates cJun, which is part of the activator protein 1 transcription factor, leading to gene transcription (83). Activation of these astrocytes led to JNK1-dependent production and release of monocyte chemoattractant protein 1 (MCP-1) amongst other chemokines (82). Using in vivo approaches, they showed that TNF $\alpha$ injection into the mouse spinal cord induced JNK-dependent mechanical allodynia and thermal hyperalgesia at $3 \mathrm{~h}$ with a concomitant increase in MCP-1 expression in astrocytes $(82,84)$. Additionally, intrathecal injection of astrocytes incubated with $\mathrm{TNF} \alpha$ were sufficient to induce MCP-1 dependent mechanical allodynia (84).
These results are paralleled with their observations in a spinal nerve ligation model of neuropathic pain, where astrocytic MCP1 is upregulated, and that pain hypersensitivity is significantly reduced by JNK inhibition and to a lesser degree by MCP-1 inhibition (82).

MCP-1 signaling via CC chemokine receptor type 2 (CCR2) modulates neuronal excitability. In culture, MCP-1 significantly reduces the responsiveness of neurons to GABA, as shown by a decrease in GABA-induced inward currents mediated by $\mathrm{GABA}_{\mathrm{A}}$ receptors (85). MCP-1 also causes significant increases in parameters indicating neuronal hyper-excitability, including decreased action potential current and voltage thresholds, as well as an increase in number of evoked action potentials (86). In spinal cord slice preparations, MCP-1 bath application dose-dependently enhances the frequency and amplitude of spontaneous EPSCs while enhancing inward AMPA and $N$ methyl-D-aspartate (NMDA) induced currents (82). Given these findings, persistent elevation of $\mathrm{MCP}-1$ by $\mathrm{TNF} \alpha$ provides a mechanism by which nociceptive sensitization may be maintained, as a constant shift toward excitation may reduce the threshold for initiating neuronal activity.

In addition to the induction of MCP-1, CCR2, which is constitutively expressed in the spinal dorsal horn (85), is upregulated in chronic pain states further amplifying the effects of MCP-1. In the peripheral nervous system, chronic compression injury to DRG neurons elevates CCR2 expression, increasing their likelihood to depolarize in response to MCP1 in vivo and in dissociated neuronal cultures $(86,87)$. In bone cancer and trigeminal neuropathic pain models, CCR2 protein expression increases significantly in neurons of the ipsilateral superficial dorsal horn and medullary dorsal horn respectively, coinciding with onset of pain hypersensitivity (88, 
89). CCR2 is also elevated in the nucleus accumbens shell where it modulates both depressive and pain-related symptoms (90), and the periaqueductal gray and rostral ventromedial medulla (24) which are involved in modulation of spinal nociceptive pathways (91).

It is likely that MCP-1 is not solely responsible for the nociceptive effects of JNK signaling, as MCP-1 inhibition only partially reduces pain hypersensitivity when compared to JNK inhibition (82). Matrix metalloproteinase-2 (MMP-2) and MMP9 , enzymes involved in degradation of the extracellular matrix [reviewed by Murphy, Nagase (92)], are also regulated by JNK signaling and secreted from astrocytes (93-95), and have been implicated in chronic pain. Work done in the hippocampus, classically associated with learning and memory rather than pain, has found that MMP-9 proteolytic activity contributes to maintenance but not induction of LTP (96), and MMP-9 alone is sufficient to enhance excitatory postsynaptic potentials and dendritic spine volume in CA1 neurons (97). In chronic pain however, while MMP-9 is upregulated in the peripheral nervous system, its expression in the CNS is minimal (98) and appears to be derived from DRG neurons rather than from astrocytes (99).

In contrast to MMP-9, delayed upregulation of MMP-2 is observed in spinal astrocytes following spinal nerve ligation, reaching significance 10 days after surgery (99). MMP-2 is sufficient to induce mechanical allodynia and is associated with cleavage of IL-1 $\beta$, a major pro-inflammatory cytokine involved in neuroinflammation which works synergistically with $\mathrm{TNF} \alpha$. IL- $1 \beta$ can stimulate additional release of MMP-2 by activating extracellular signal-regulated kinase (ERK) 1/2 in astrocytes (99). Later work has identified the induction of neuronal MMP-2 at an earlier time point, coinciding approximately with symptom onset in a chronic post-ischemia pain model (100). Inhibiting MMP-2 reduces spinal GFAP levels along with decreased phosphorylation of JNK1/2 following induction of chronic pain (100). Thus, elevated neuronal MMP-2 may initially contribute to the induction of astrogliosis in the spinal cord, resulting in the phosphorylation of JNK in astrocytes, and release of both MMP-2 and MCP-1 during the chronic phase of pain. In line with this potential chain of events, there is some evidence suggesting a delay between onset of behavioral symptoms and elevated phosphorylation of JNK1. In two models of neuropathic pain, whereas behavioral symptoms manifested in under a day, increases in pJNK1 levels in the spinal dorsal horn were not observed until day 3 in a spinal nerve ligation model (101) or day 7 in a spared nerve injury model (102), suggesting a potential role for JNK1 in the transition from acute to chronic pain. Accordingly, in a CFA model of chronic inflammatory pain, whereas chronic intrathecal infusion of the JNK1 inhibitor D-JNKI-1 failed to reduce mechanical allodynia during the induction phase, tested at $6 \mathrm{~h}$ post CFA injection, it significantly reduced allodynia during the maintenance phase tested days 14 post CFA injection (103). In contrast, a study employing a mouse model of chronic post-ischemia pain observed elevations in pJNK1 at the same time as the development of behavioral symptoms (100), and JNK inhibition produced a significant analgesic effect at pain onset, indicating mechanistic differences in chronic pain development resulting from different injuries.

\section{GLIOTRANSMISSION IN CHRONIC PAIN}

Beyond their role in inflammatory signaling, astrocytes can detect neuronal activity through a variety of membrane receptors, inducing intracellular $\mathrm{Ca}^{2+}$ responses $(104,105)$ and subsequent release of neuromodulatory substances, known as gliotransmitters (106-108); these include glutamate, GABA, adenosine-5'-triphosphate (ATP), and D-serine, which bind to an array of pre- and post-synaptic neuronal receptors and influence synaptic transmission (109). The relevance of gliotransmission in chronic pain is currently under debate $(110,111)$, however emerging evidence indicates a potential role in chronic pain, including findings that gliotransmission is enhanced in reactive astrocytes (112-116) and modulated by inflammatory mediators $(117,118)$.

$\mathrm{D}$-serine is a potent co-agonist which binds to the glycine site of NMDA receptors (119). It is synthesized by the enzyme serine racemase, which catalyzes the conversion of L-serine to D-serine (120). While serine racemase is primarily expressed in neurons (121), recent evidence shows that reactive astrocytes in traumatic brain injury, Alzheimer's disease, and pain models express the enzyme $(115,116,122)$. D-serine released by reactive astrocytes is implicated in the expression of dynamic mechanical allodynia in chronic and acute models of orofacial pain, as well as static allodynia in chronic neuropathic pain (122-125). In these models, degradation of $\mathrm{D}$-serine by $\mathrm{D}$-amino acid oxidase or inhibition of serine racemase by L-serine O-sulfate can prevent the induction of mechanical allodynia, or reduce mechanical allodynia after onset (122-125). Despite neurons being capable of releasing D-serine (126), the finding that astrocyte inhibition reduces mechanical allodynia, which can be reversed by exogenous $\mathrm{D}$-serine further suggests the specific requirement for astrocytes as a source of D-serine (124).

Another gliotransmitter that has been identified as a potential player in chronic pain is ATP. ATP acts primarily through the ionotropic P2X and metabotropic P2Y purinergic receptor families, which are expressed on many cell types in the CNS including neurons, astrocytes, and microglia [for a review see Burnstock (127)]. P2X receptor activation facilitates synaptic transmission by increasing presynaptic glutamate release (128, 129) and inducing EPSCs (130-132), while P2Y receptors primarily mediate inhibitory effects by reducing presynaptic glutamate release $(129,133)$. However, its functions at excitatory synapses are increasingly observed to be quite complex.

Work by Zhang et al. $(134,135)$ has provided evidence for the involvement of purinergic signaling on neurons in rats with chronic visceral hypersensitivity, showing that $\mathrm{P}_{2} \mathrm{X}_{7}$ and $\mathrm{P} 2 \mathrm{X}_{3}$ are both upregulated and colocalize with the presynaptic marker synaptophysin in the insular cortex $(134,135)$. Additionally, inhibitors for either $\mathrm{P}_{2} \mathrm{X}_{7}$ or $\mathrm{P}_{2} \mathrm{X}_{3}$ reduced glutamatergic synaptic activity and pain-like symptoms, whereas agonists for either receptor had the opposite effect, elevating synaptic activity and inducing visceral hypersensitivity. Although the cellular source of ATP and whether it was enhanced was not tested in this model, studies by two separate groups in neuropathic pain models have found evidence suggesting that astrocytic ATP release in the spinal cord contributes 
to pain hypersensitivity. One study by Cui et al. (136) found that inhibiting the mammalian target of rapamycin signaling pathway could reduce ATP release from cultured astrocytes and inhibit neuropathic pain-induced ATP elevation in cerebral spinal fluid. They associated this finding with the analgesic effect of rapamycin (136). Koyanagi et al. (137) investigated diurnal fluctuations in glucocorticoids and its effects on mechanical allodynia and observed that oscillations of plasma corticosterone levels corresponded to the oscillations of spinal ATP and mechanical allodynia. Intrathecal corticosterone injection induced mechanical allodynia which was dependent on microglial $\mathrm{P}_{2} \mathrm{Y}_{12}$ and also induced ATP release from cultured astrocytes via serum/glucocorticoid regulated kinase 1 signaling (137). Here again like cytokine signaling, ATP signaling involves both astrocytes and microglia and represents another mechanism by which they can interact. Mixed glial culture studies have shown that activation of microglial P2 receptors by either exogenous or astrocyte-derived ATP induces the release of extracellular vesicles, which can in turn modify astrocyte activity $(138,139)$. Additionally, microglia can release ATP, which has been shown to indirectly modulate excitatory neuronal activity through binding to astrocytic $\mathrm{P}_{2} \mathrm{Y}_{1}$ receptors in hippocampal slices (113). These findings provide a functional basis which may translate to pain-associated areas in the CNS. Indeed, studies in neuropathic pain models have associated the induction and activity of spinal microglia P2 receptors with the development of mechanical hypersensitivity $(140,141)$ [for a more in-depth discussion see review by Trang et al. (142)]. Given the variety of cells that can both release and respond to ATP, there is insufficient data to determine whether direct astrocyte to neuron purinergic signaling in the CNS is involved in chronic pain. However, due to the evidence for purinergic signaling in modulating synaptic activity, it remains a possible pathway by which astrocytes can influence maladaptive plasticity in nociceptive circuits of the CNS.

\section{ALTERED GLUTAMATE-GLUTAMINE CYCLING IN CHRONIC PAIN}

In addition to the release of neuromodulatory substances, astrocytes are metabolically coupled to neurons. They participate in glutamate clearance by taking up glutamate present at the synaptic cleft, which can then be converted to glutamine via glutamine synthetase (GS) and exported in a process known as the glutamate-glutamine cycle (143). Mounting human and animal data suggest that the development of chronic pain may also involve changes in glutamate-glutamine homeostasis. For example, in healthy human subjects, glutamate and glutamine levels positively correlate with subjective evoked pain ratings in pain-associated areas such as the ACC, mid-cingulate cortex, insula, dorsolateral prefrontal cortex, and thalamus $(144,145)$. Moreover, elevated combined levels of glutamate and glutamine have been observed in the ACC of patients with a range of chronic pain conditions (146), the thalamus of migraine patients (147), and in the right amygdala of female fibromyalgia patients (148). Notably, glutamate uptake by astrocytes, which is mediated via the glutamate transporters GLT-1 and GLAST (149), appears to show biphasic alterations in rodent models of neuropathic pain. Specifically, within the first 5 days following nerve injury, astrocytic expression of both in GLT-1 and GLAST is upregulated in the ipsilateral spinal dorsal horn $(150,151)$, which is followed by a prominent decrease in expression below baseline at 7 days post-injury and beyond (150-153). Critically, changes in glutamate uptake may play a causal role in chronic pain development, as inhibiting glutamate transporter upregulation enhances the onset and magnitude of pain-related behaviors (151), whereas transgenic upregulation of spinal GLT1 can disrupt the induction of, and partially reverse, mechanical and thermal hypersensitivity in neuropathic and inflammatory pain models $(154,155)$. Interestingly, upregulation of GLT1 was associated with a decreased number of dorsal horn neurons expressing the immediate early gene $\Delta \mathrm{FosB}$, indicating a reduction in neuronal activity (155). Additionally, acute inhibition of spinal GS has also been found to transiently reduce mechanical allodynia in a rat model of chronic pulpitis (156). This was accompanied by a reduction in the enhanced response of wide dynamic range neurons, located in the medullary dorsal horn, to mechanical stimulation (156). There are some discrepancies in the literature, as it has been found for example that intracisternal injection of DL-threo- $\beta$-benzyloxyaspartate, an inhibitor of GLT-1, GLAST, and the neuronal glutamate transporter EAAC1, can reduce rather than enhance CFAinduced orofacial heat hyperalgesia (157). Despite this, the evidence suggests that glutamate-glutamine cycling is altered in chronic pain states. It should be noted however, that while GLT-1 and GLAST are predominantly expressed on astrocytes, microglia in the spinal cord and brainstem have been shown to express both transporters following peripheral nerve injury $(152,158)$ and likely participate in mediating aberrant glutamate dynamics.

\section{THE ASTROCYTE-NEURON LACTATE SHUTTLE}

Astrocyte-neuronal metabolic coupling may also play a critical role in the development of chronic pain. Pain-induced neuroplasticity within spinal and brain regions is believed to promote the transition from acute to chronic pain, and mounting evidence indicates that astrocytes provide neurons with energy in an activity-dependent manner. In particular, astrocytes are the primary sites of glycogen storage in the CNS (159). In response to neuronal activity, astrocytes can rapidly metabolize glycogen to lactate (160) and export it to neurons, where it is converted to pyruvate, and metabolized to ATP via the citric acid cycle and oxidative phosphorylation to serve as a source of energy (161-163). L-lactate derived from astrocytes has been investigated as an energy source for neurons, and altered lactate metabolism is associated with diseases such as Alzheimer's (164-166), epilepsy (167), multiple sclerosis (168, 169), and depression (170). Astrocyte metabolism can also be significantly modified by a variety of cytokines (171). Therefore, it is of 


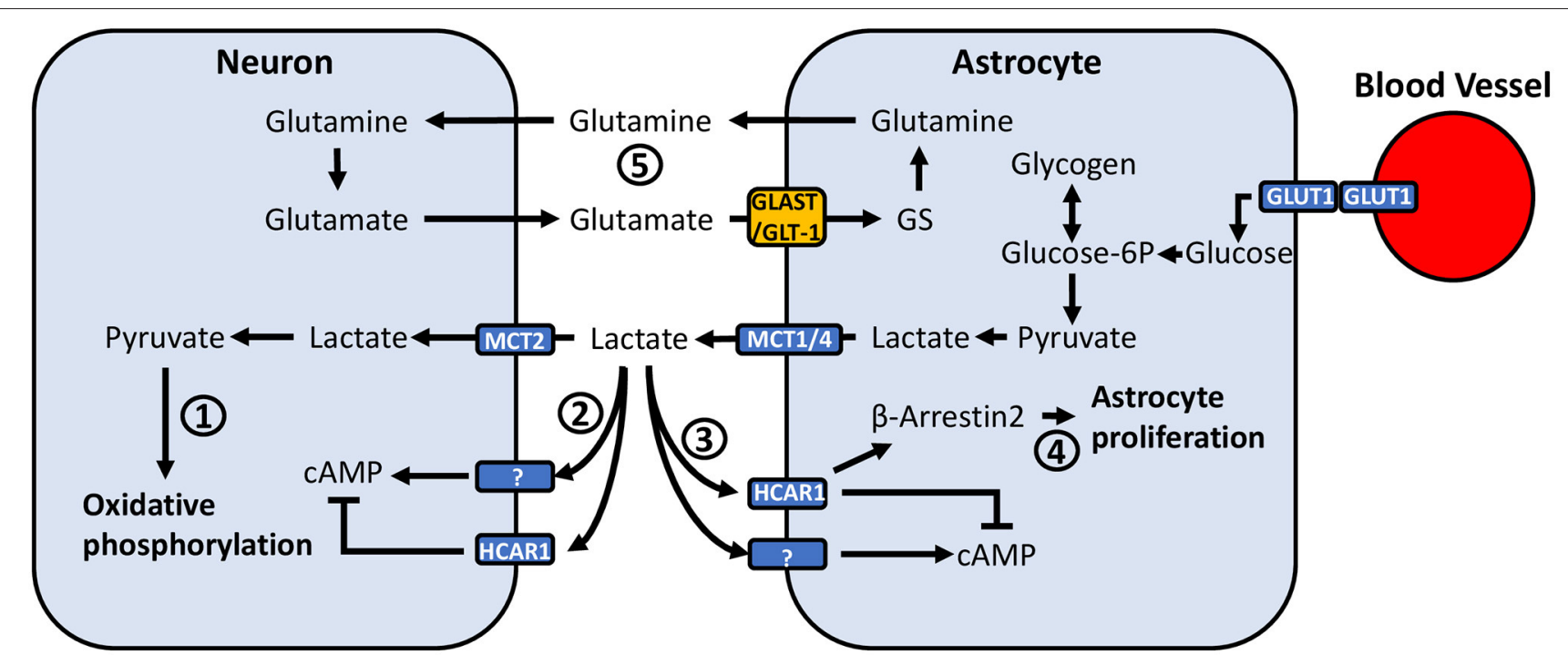

FIGURE 2 | Potential mechanisms through which astrocyte-neuronal metabolic coupling and lactate release can mediate pain-related neuronal activity. (1) Lactate taken up by neurons via MCT2 is converted to pyruvate, where it can be used to generate ATP through oxidative phosphorylation. (2) Neurons express HCAR1, a $\mathrm{G}_{\mathrm{i}}$-protein coupled receptor which inhibits adenylyl cyclase and reduces intracellular cAMP. Neurons also appear to express an unidentified lactate receptor which activates adenylyl cyclase and increases cAMP. (3) Similarly, astrocytes have been found to express HCAR1, however recent findings also suggest the presence of a lactate receptor which exerts opposite effects and activates rather than inhibits adenylyl cyclase. (4) Lactate binding to HCAR1 was recently associated with a non-Gi-protein mechanism, acting through $\beta$-arrestin2-MAPK-signaling. The $\beta$-arrestin2-MAPK pathway has been associated with induction of astrocyte proliferation. (5) Glutamate released into the synaptic cleft is taken up by astrocytes via GLT-1 and GLAST. Astrocytic GS converts glutamate to glutamine, which is exported and taken up by neurons. Altered GLT-1/GLAST expression may affect synaptic transmission through dysregulation of extracellular glutamate concentrations.

interest whether altered astrocytic lactate dynamics are involved in the development and maintenance of chronic pain.

Due to their close association with both neurons and blood vessels in the CNS, astrocytes are in a prime position to mediate energy supply to neurons (Figure 2). Astrocyte end feed processes make contact with blood vessels (172), allowing them to take up glucose from the blood via glucose transporter 1 (GLUT1) (173). Early culture studies demonstrated that astrocytes are able to accumulate glycogen in the presence of glucose (160). While both neurons and astrocytes express glycogen synthase $(174,175)$, a critical enzyme in glycogenesis, brain glycogen is predominantly localized to astrocytes rather than neurons (159). Astrocytes can break down glycogen to produce lactate (160), the majority of which is exported to the extracellular space rather than being consumed for energy $(161,162)$. In addition to findings that astrocytes can store glucose and export lactate, mechanisms by which lactate release is coupled to neuronal activity have been identified. Seminal work by Pellerin and Magistretti showed that glutamate uptake by astrocytes stimulates glucose uptake, glycolysis and lactate release, an effect dependent on extracellular $\mathrm{Na}+$ and glutamate co-transport $(176,177)$. Further work identifying the expression of monocarboxylate transporters (MCT) in the brain, localization of different isoforms of lactate dehydrogenase in neurons and astrocytes, and that lactate was an efficient substrate for oxidative metabolism led to the proposal of the astrocyte neuron-lactate shuttle (178). This theory proposed that neuronal activity stimulates glycogenolysis and conversion of glucose to lactate, followed by its subsequent release from astrocytes and uptake by neurons to produce ATP during elevated activity (178).

Much of the work examining the consequences of lactate shuttling have been in the context of learning, memory, and reward associated learning in the brain. The formation of long-term memories has been shown to require hippocampal astrocytic lactate release during the initial acquisition period $(179,180)$. Indeed, training in an inhibitory avoidance task is accompanied by a rapid and sustained increase in extracellular lactate in the hippocampus (179), whereas inhibiting glycogen phosphorylase, the rate limiting enzyme in glycogenolysis, using 1,4-dideoxy-1,4,-imino-D-arabinitol $15 \mathrm{~min}$ prior to training abolishes the lactate rise, impairs LTP, and results in memory deficits $(179,180)$. In addition, inhibiting astrocytic lactate export by reducing MCT1 or MCT4 expression, or blocking neuronal lactate uptake by reducing MCT2 expression both result in memory impairments (179-181). The former can be rescued by lactate and its energetic equivalent pyruvate, but not by glucose $(179,180)$. Similar findings have been observed in drug-related memories involving the amygdala. In a conditioned place preference (CPP) paradigm, inhibiting glycogenolysis in the basolateral amygdala can prevent the acquisition of cocaine-induced place preference, transiently inhibit established CPP, and impair CPP following retrieval (182, 183). In both the hippocampus and amygdala, the induction of plasticity-related phosphorylation of cAMP response-element binding protein (CREB), cofilin, and ERK, is dependent on astrocytic glycogenolysis and L-lactate $(179,182)$. Notably, CREB 
is activated in the spinal cord and forebrain following tissue injury $(184,185)$, and transgenic over-expression of CREB in the forebrain enhances behavioral responses to the formalin model of temporary pain, and correspond with potentiated and more rapid development of pain hypersensitivity induced by nerve injury (186). Given that long term memory and chronic pain both involve persistent changes in synaptic activity, it is of interest whether astrocyte-neuronal lactate shuttling is involved in the pathogenesis of chronic pain.

\section{INITIAL RESEARCH ON ASTROCYTE LACTATE EXPORT IN CHRONIC PAIN}

Very few studies have directly examined the involvement of astrocyte-derived lactate in the context of pain. However, there is some evidence associating chronic pain with altered lactate dynamics in the CNS. One study found that MCT1 protein expression is elevated in the spinal dorsal horn 7 days after induction of chronic inflammatory pain by CFA (187), an observation that was also made in the hippocampus following inhibitory avoidance training (179). Another study in rats with chronic visceral hypersensitivity observed blunted activitydependent lactate release in the ACC along with impaired decision making and synaptic plasticity (16). Additionally, molecular changes associated with long-term potentiation, such as the upregulation of pCREB or pERK in the spinal dorsal horn and the spinothalamic tract $(10,188-192)$, as well as in supraspinal regions such as the amygdala and anterior cingulate cortex (193-195) are also observed in chronic pain states. These parallels with memory-related synaptic plasticity suggest the possibility of other common mechanisms such as lactate shuttling in chronic pain. Recent work by Miyamoto et al. (196) showed that activating spinal astrocytes in mice using designer receptors exclusively activated by designer drugs (DREADDs) rapidly induces mechanical allodynia lasting for $10 \mathrm{~h}$, accompanied by an increase in extracellular lactate levels. Accordingly, the broad MCT inhibitor $\alpha$-Cyano-4-hydroxycinnamic acid (4-CIN) fully reversed this induced allodynia (196). They also found that intrathecal injections of 4-CIN could reduce mechanical allodynia, although not fully, in a partial sciatic nerve ligation model of neuropathic pain (196). At the time of drug administration, behavioral symptoms have already developed suggesting that inhibiting lactate shuttling can reduce pain hypersensitivity during the chronic phase. A study by a separate group also found that 4-CIN could partially alleviate mechanical allodynia during the chronic phase of a spinal-nerve ligation pain model (197). Hence, this initial evidence points to a possible role of spinal astrocytic lactate in maintaining pain hypersensitivity. This is a departure from findings in long term memory, where disrupting lactate beyond a certain window of time following either memory acquisition or retrieval has no effect on subsequent task performance $(179,182)$.

In addition to the work above, there have been studies which investigated pyruvate kinase M2 (PKM2), a glycolytic enzyme that catalyzes the dephosphorylation of phosphoenolpyruvate to pyruvate. Expression of PKM2 is elevated in the spinal dorsal horn along with lactate in both neuropathic and inflammatory pain models $(198,199)$. Inhibiting PKM2 reduces lactate elevations and partially alleviates mechanical allodynia and thermal hyperalgesia $(198,199)$. However, these studies also noted that inhibiting PKM2 prevented the enhanced expression of GFAP, TNF $\alpha$, IL-1 $\beta$, and phosphorylation of STAT3 amongst other proteins $(198,199)$. Indeed, PKM2 has been implicated to have functions beyond glycolysis, including activity as a protein kinase [see review by Dong et al. (200)]. But these effects may also relate to possible lactate signaling which will be discussed below. It is however, difficult to isolate the PKM2-mediated rise in lactate to astrocytes in these studies, as PKM2 expression was elevated in neurons and microglia as well (199).

\section{LACTATE SIGNALING ON NEURONAL EXCITABILITY AND PLASTICITY}

Beyond acting as a metabolic substrate for ATP production, evidence for a signaling role of lactate complicates its effects in the CNS (Figure 2). The production of NADH by lactate in neurons has been shown to induce the expression of the plasticity-related immediate early genes Arc, c-Fos and Zif268 (201). Additionally, neurons in the brain express the extracellular hydroxycarboxylic acid receptor 1 (HCAR1), a $\mathrm{G}_{\mathrm{i}}$-protein coupled receptor which inhibits adenylyl cyclase and reduces intracellular cAMP (202, 203). L-lactate has been found to decrease the firing frequency of CA1 pyramidal cells in hippocampal slices, as well as in primary cortical neuron cultures via activation of HCAR1 $(203,204)$. Conversely, L-lactate can potentiate EPSCs, firing frequency, and spike probability of pyramidal cells in the CA3 region of hippocampal slices (205), and similarly increase firing frequency and neurotransmitter release in locus coeruleus slices (206) via a lactate receptor that has yet to be characterized (205-207). These effects are suggested to be metabolism-independent and mediated by extracellular signaling due to insensitivity to 4 -CIN (204-206). These findings raise the possibility that population differences in the effects of extracellular lactate signaling may result in differential regulation of synaptic activity at various points along nociceptive signaling pathways.

\section{LACTATE SIGNALING IMPLICATED IN ALTERING ASTROCYTE FUNCTION}

Astrocytes may also respond to lactate (Figure 2), as they express HCAR1 (202, 208), which was recently associated with reducing glutamate-induced calcium influx via $\beta$-arrestin2MAPK signaling (209). Kappa-opioid receptor activation of the $\beta$-arrestin2-ERK1/2 pathway induces astrocyte proliferation in vitro (210), and kappa-opioid receptor activation of p38-MAPK, which is also regulated by $\beta$-arrestin2 (211), has been implicated in astrocyte proliferation following sciatic nerve ligation in mice (212). Thus, lactate may promote astrocyte proliferation via a common intracellular signaling pathway, contributing to reactive astrogliosis. Recent findings have also identified that lactate can induce rises in intracellular cAMP and lactate via activation of adenylyl cyclase, suggesting the presence of another 
uncharacterized lactate receptor (213). cAMP is involved in a variety of signaling pathways and can modulate inducible nitricoxide synthase activity $(214,215)$, cytokine release $(216,217)$, and astrocyte morphology (218).

Astrocytes in primary astroglial cultures incubated with $25 \mathrm{mM}$ lactate show a significant increase in release of $\mathrm{TNF} \alpha$ and IL-6 (219). Recent research in diabetic mice found that pyruvate dehydrogenase 2 (PDK2) expression was enhanced in hypothalamic astrocytes and contributed to inflammation (220). PDK2 phosphorylates and deactivates pyruvate dehydrogenase (221), shifting pyruvate metabolism to form lactate rather than enter the citric acid cycle. Genetically knocking out PDK2 reduced diabetes-induced elevation of lactate and induction of TNF $\alpha$, IL- $1 \beta$ and IL-6, providing additional albeit indirect evidence for lactate-induced cytokine release (220). Furthermore, lactate uptake through MCT1 in oxygen and glucose deprived astrocyte cultures can upregulate expression of GFAP and phosphorylation of Akt and STAT3 (222); STAT3 is involved in reactive astrogliosis (223). These findings raise the possibility that aberrant lactate dynamics may facilitate astrocyte activation and their subsequent inflammatory cytokine profiles. However, given the expression of potentially two lactate receptors with opposing effects on adenylyl cyclase-cAMP signaling, the net effect of lactate on astrocytes in chronic pain is unclear.

Recent work by Bingul et al. (224) has provided interesting insight into long term lactate dynamics in vivo following LTP in the dentate gyrus of rats, with implications for lactate both as an energy substrate but also as a signaling molecule. Extracellular lactate levels change within seconds in response to acute electrical stimulation of the medial perforant pathway (224). The response is characterized by an initial dip in extracellular lactate followed by a larger overshoot, before returning to baseline (224). LTP induction causes a significant increase in the magnitude of the lactate dips and overshoots, starting at $24 \mathrm{~h}$ after potentiation, and induces an average chronic elevation of lactate concentrations that persists for $72 \mathrm{~h}$ (224). Whether these findings, in addition to lactate signaling described earlier, translates to $\mathrm{CNS}$ areas associated with mediating persistent pain has yet to be investigated, but they give rise to interesting possibilities. In the context of chronic pain, potentiated synaptic activity in the central nervous system may maintain persistently

\section{REFERENCES}

1. Kuner R, Flor H. Structural plasticity and reorganisation in chronic pain. Nat Rev Neurosci. (2016) 18:20-30. doi: 10.1038/nrn.2016.162

2. Luo C, Kuner T, Kuner R. Synaptic plasticity in pathological pain. Trends Neurosci. (2014) 37:343-55. doi: 10.1016/j.tins.2014.04.002

3. Sofroniew MV. Molecular dissection of reactive astrogliosis and glial scar formation. Trends Neurosci. (2009) 32:63847. doi: 10.1016/j.tins.2009.08.002

4. Colangelo AM, Alberghina L, Papa M. Astrogliosis as a therapeutic target for neurodegenerative diseases. Neurosci Lett. (2014) 565:5964. doi: 10.1016/j.neulet.2014.01.014

5. Zamanian JL, Xu L, Foo LC, Nouri N, Zhou L, Giffard RG, et al. Genomic analysis of reactive astrogliosis. J Neurosci. (2012) 32:6391410. doi: 10.1523/JNEUROSCI.6221-11.2012 elevated extracellular lactate levels via activity-dependent release from astrocytes. Lactate, in addition to its metabolic role, is therefore in a position to mediate persistent effects on both astrocytes and neurons via extracellular receptor binding. However, lactate's functions as a signaling molecule in the CNS both under healthy and pathological conditions is poorly understood, requiring further research on how it may contribute to pathology.

\section{CONCLUSION}

Astrocytes release a variety of metabolites and cytokines which have profound effects on neuronal activity. Pathology of the CNS is often associated with reactive astrogliosis, which is accompanied by altered release of these neuromodulatory substances. The findings presented here provide evidence for the involvement of altered astrocytic cytokine release in long term synaptic plasticity of central nociceptive pathways under chronic pain states. Gliotransmitters have also been implicated but given that microglia are involved in ATP and D-serine signaling, whether direct astrocyte-neuronal communication via altered gliotransmission contributes to the pathology of chronic pain is unclear. Lastly, the role of lactate derived from astrocytes as a neuronal energy substrate, and more recently as a signaling molecule in the CNS, has evolved significantly. However, very few studies have examined the involvement of lactate in the development and maintenance of chronic pain, presenting an exciting pathway for further research.

\section{AUTHOR CONTRIBUTIONS}

JT and MB drafted the review. JT formatted Figures 1, 2. JT and GD formulated the idea for the review and GD guided the research and writing process. All authors contributed to the article and approved the submitted version.

\section{FUNDING}

This work was supported by a NARSAD Young Investigator Grant (grant numbers 27275 and 29558) and an Azrieli Foundation Back on Track from COVID19 (grant number 054812) to GD.

6. Cao J, Wang J-S, Ren X-H, Zang W-D. Spinal sample showing p-JNK and P38 associated with the pain signaling transduction of glial cell in neuropathic pain. Spinal Cord. (2015) 53:92-7. doi: 10.1038/sc.201 4.188

7. Ma W, Quirion R. Partial sciatic nerve ligation induces increase in the phosphorylation of extracellular signal-regulated kinase (ERK) and c-Jun N-terminal kinase (JNK) in astrocytes in the lumbar spinal dorsal horn and the gracile nucleus. Pain. (2002) 99:175-84. doi: 10.1016/S0304-3959(02)00097-0

8. Wang W, Mei X-P, Wei Y-Y, Zhang M-M, Zhang T, Wang W, et al. Neuronal NR2B-containing NMDA receptor mediates spinal astrocytic cJun N-terminal kinase activation in a rat model of neuropathic pain. Brain Behav Immun. (2011) 25:1355-66. doi: 10.1016/j.bbi.2011.04.002

9. Tang J, Zhu C, Li Z-h, Liu X-y, Sun S-k, Zhang T, et al. Inhibition of the spinal astrocytic JNK/MCP-1 pathway activation correlates with 
the analgesic effects of tanshinone IIA sulfonate in neuropathic pain. $J$ Neuroinflammation. (2015) 12:57. doi: 10.1186/s12974-015-0279-7

10. Paszcuk AF, Dutra RC, da Silva KABS, Quintão NLM, Campos MM, Calixto JB. Cannabinoid agonists inhibit neuropathic pain induced by brachial plexus avulsion in mice by affecting glial cells and MAP kinases. PLoS ONE. (2011) 6:e24034. doi: 10.1371/journal.pone.0024034

11. Romero-Sandoval A, Chai N, Nutile-McMenemy N, DeLeo JA. A comparison of spinal Ibal and GFAP expression in rodent models of acute and chronic pain. Brain Res. (2008) 1219:116-26. doi: 10.1016/j.brainres.2008.05.004

12. Masocha W. Astrocyte activation in the anterior cingulate cortex and altered glutamatergic gene expression during paclitaxel-induced neuropathic pain in mice. PeerJ. (2015) 2015:e1350. doi: 10.7717/peerj.1350

13. Chen FL, Dong YL, Zhang ZJ, Cao DL, Xu J, Hui J, et al. Activation of astrocytes in the anterior cingulate cortex contributes to the affective component of pain in an inflammatory pain model. Brain Res Bull. (2012) 87:60-6. doi: 10.1016/j.brainresbull.2011.09.022

14. Kuzumaki N, Narita M, Narita M, Hareyama N, Niikura K, Nagumo Y, et al. Chronic pain-induced astrocyte activation in the cingulate cortex with no change in neural or glial differentiation from neural stem cells in mice. Neurosci Lett. (2007) 415:22-7. doi: 10.1016/j.neulet.2006.12.057

15. Ikeda $H$, Mochizuki $K$, Murase $K$. Astrocytes are involved in long-term facilitation of neuronal excitation in the anterior cingulate cortex of mice with inflammatory pain. Pain. (2013) 154:2836-43. doi: 10.1016/j.pain.2013.08.023

16. Wang J, Tu J, Cao B, Mu L, Yang X, Cong $\mathrm{M}$, et al. Astrocytic L-lactate signaling facilitates amygdala-anterior cingulate cortex synchrony and decision making in rats. Cell Rep. (2017) 21:2407-18. doi: 10.1016/j.celrep.2017.11.012

17. Kim SK, Hayashi H, Ishikawa T, Shibata K, Shigetomi E, Shinozaki Y, et al. Cortical astrocytes rewire somatosensory cortical circuits for peripheral neuropathic pain. J Clin Invest. (2016) 126:1983-97. doi: 10.1172/JCI82859

18. Burke NN, Geoghegan E, Kerr DM, Moriarty O, Finn DP, Roche M. Altered neuropathic pain behaviour in a rat model of depression is associated with changes in inflammatory gene expression in the amygdala. Genes Brain Behav. (2013) 12:705-13. doi: 10.1111/gbb.12080

19. Marcello L, Cavaliere C, Colangelo AM, Bianco MR, Cirillo G, Alberghina L, et al. Remodelling of supraspinal neuroglial network in neuropathic pain is featured by a reactive gliosis of the nociceptive amygdala. Eur J Pain. (2013) 17:799-810. doi: 10.1002/j.1532-2149.2012.00255.x

20. Blaszczyk L, Maître M, Lesté-Lasserre T, Clark S, Cota D, Oliet SHR, et al. Sequential alteration of microglia and astrocytes in the rat thalamus following spinal nerve ligation. J Neuroinflammation. (2018) 15:349. doi: 10.1186/s12974-018-1378-Z

21. Ni H-D, Yao M, Huang B, Xu L-S, Zheng Y, Chu Y-X, et al. Glial activation in the periaqueductal gray promotes descending facilitation of neuropathic pain through the p38 MAPK signaling pathway. J Neurosci Res. (2016) 94:50-61. doi: 10.1002/jnr.23672

22. Mor D, Bembrick AL, Austin PJ, Wyllie PM, Creber NJ, Denyer GS, et al. Anatomically specific patterns of glial activation in the periaqueductal gray of the sub-population of rats showing pain and disability following chronic constriction injury of the sciatic nerve. Neuroscience. (2010) 166:116784. doi: 10.1016/j.neuroscience.2010.01.045

23. Ni HD, Xu LS, Wang Y, Li H, An K, Liu M, et al. Astrocyte activation in the periaqueductal gray promotes descending facilitation to cancer-induced bone pain through the JNK MAPK signaling pathway. Mol Pain. (2019) 15:174480691983190. doi: 10.1177/1744806919831909

24. Dubový P, Klusáková I, Hradilová-SvíŽenská I, Joukal M, Boadas-Vaello P. Activation of astrocytes and microglial cells and CCL2/CCR2 upregulation in the dorsolateral and ventrolateral nuclei of periaqueductal gray and rostral ventromedial medulla following different types of sciatic nerve injury. Front Cell Neurosci. (2018) 12:40. doi: 10.3389/fncel.2018.00040

25. Di Cesare Mannelli L, Pacini A, Micheli L, Tani A, Zanardelli M, Ghelardini C. Glial role in oxaliplatin-induced neuropathic pain. Exp Neurol. (2014) 261:22-33. doi: 10.1016/j.expneurol.2014.06.016

26. Obata H, Eisenach JC, Hussain H, Bynum T, Vincler M. Spinal glial activation contributes to postoperative mechanical hypersensitivity in the rat. J Pain. (2006) 7:816-22. doi: 10.1016/j.jpain.2006.04.004
27. Xu Y, Cheng G, Zhu Y, Zhang X, Pu S, Wu J, et al. Anti-nociceptive roles of the glia-specific metabolic inhibitor fluorocitrate in paclitaxel-evoked neuropathic pain. Acta Biochim Biophys Sin (Shanghai). (2016) 48:9028. doi: 10.1093/abbs/gmw083

28. Kosek E, Martinsen S, Gerdle B, Mannerkorpi K, Löfgren M, BileviciuteLjungar I, et al. The translocator protein gene is associated with symptom severity and cerebral pain processing in fibromyalgia. Brain Behav Immun. (2016) 58:218-27. doi: 10.1016/j.bbi.2016.07.150

29. Albrecht DS, Ahmed SU, Kettner NW, Borra RJH, CohenAdad J, Deng $\mathrm{H}$, et al. Neuroinflammation of the spinal cord and nerve roots in chronic radicular pain patients. Pain. (2018) 159:968-77. doi: 10.1097/j.pain.0000000000001171

30. Loggia ML, Chonde DB, Akeju O, Arabasz G, Catana C, Edwards RR, et al. Evidence for brain glial activation in chronic pain patients. Brain. (2015) 138:604-15. doi: 10.1093/brain/awu377

31. Albrecht DS, Kim M, Akeju O, Torrado-Carvajal A, Edwards RR, Zhang Y, et al. The neuroinflammatory component of negative affect in patients with chronic pain. Mol Psychiatry. (2019) 26:864-74. doi: 10.1038/s41380-019-0433-1

32. Shi Y, Gelman BB, Lisinicchia JG, Tang SJ. Chronic-pain-associated astrocytic reaction in the spinal cord dorsal horn of human immunodeficiency virus-infected patients. J Neurosci. (2012) 32:10833-40. doi: 10.1523/JNEUROSCI.5628-11.2012

33. Zhang JM, An J. Cytokines, inflammation, and pain. Int Anesthesiol Clin. (2007) 45:27-37. doi: 10.1097/AIA.0b013e318034194e

34. Zhu MD, Zhao LX, Wang XT, Gao YJ, Zhang ZJ. Ligustilide inhibits microglia-mediated proinflammatory cytokines production and inflammatory pain. Brain Res Bull. (2014) 109:5460. doi: 10.1016/j.brainresbull.2014.10.002

35. Detloff MR, Fisher LC, McGaughy V, Longbrake EE, Popovich PG, Basso DM. Remote activation of microglia and pro-inflammatory cytokines predict the onset and severity of below-level neuropathic pain after spinal cord injury in rats. Exp Neurol. (2008) 212:337-47. doi: 10.1016/j.expneurol.2008.04.009

36. Honjoh K, Nakajima H, Hirai T, Watanabe S, Matsumine A. Relationship of inflammatory cytokines from M1-type microglia/macrophages at the injured site and lumbar enlargement with neuropathic pain after spinal cord injury in the CCL21 Knockout (plt) Mouse. Front Cell Neurosci. (2019) 13:525. doi: 10.3389/fncel.2019.00525

37. Ledeboer A, Sloane EM, Milligan ED, Frank MG, Mahony JH, Maier SF, et al. Minocycline attenuates mechanical allodynia and proinflammatory cytokine expression in rat models of pain facilitation. Pain. (2005) 115:7183. doi: 10.1016/j.pain.2005.02.009

38. Sun JS, Yang YJ, Zhang YZ, Huang W, Li ZS, Zhang Y. Minocycline attenuates pain by inhibiting spinal microglia activation in diabetic rats. $\mathrm{Mol}$ Med Rep. (2015) 12:2677-82. doi: 10.3892/mmr.2015.3735

39. Inoue K, Tsuda M. Microglia in neuropathic pain: cellular and molecular mechanisms and therapeutic potential. Nat Rev Neurosci. (2018) 19:13852. doi: 10.1038/nrn.2018.2

40. Mika J. Modulation of microglia can attenuate neuropathic pain symptoms and enhance morphine effectiveness. Pharmacol Rep. (2008) 60:297-307.

41. Lieberman AP, Pitha PM, Shin HS, Shin ML. Production of tumor necrosis factor and other cytokines by astrocytes stimulated with lipopolysaccharide or a neurotropic virus. Proc Natl Acad Sci USA. (1989) 86:634852. doi: $10.1073 /$ pnas.86.16.6348

42. Lau LT, Yu ACH. Astrocytes produce and release interleukin-1, interleukin-6, tumor necrosis factor alpha and interferon-gamma following traumatic and metabolic injury. J Neurotrauma. (2001) 18:351-59. doi: 10.1089/08977150151071035

43. Fernandes A, Silva RFM, Falcão AS, Brito MA, Brites D. Cytokine production, glutamate release and cell death in rat cultured astrocytes treated with unconjugated bilirubin and LPS. J Neuroimmunol. (2004) 153:6475. doi: 10.1016/j.jneuroim.2004.04.007

44. Chung IY, Benveniste EN. Tumor necrosis factor-alpha production by astrocytes. Induction by lipopolysaccharide, IFN-gamma, and IL-1 beta. J Immunol. (1990) 144:2999-3007.

45. Brodie C, Weizman N, Katzoff A, Lustig S, Kobiler D. Astrocyte activation by Sindbis virus: expression of GFAP, cytokines, and adhesion molecules. Glia. (1997) 19:275-85. 
46. Ji X-T, Qian N-S, Zhang T, Li J-M, Li X-K, Wang P, et al. Spinal astrocytic activation contributes to mechanical allodynia in a rat chemotherapy-induced neuropathic pain model. PLoS ONE. (2013) 8:e60733. doi: 10.1371/journal.pone.0060733

47. Backonja MM, Coe CL, Muller DA, Schell K. Altered cytokine levels in the blood and cerebrospinal fluid of chronic pain patients. J Neuroimmunol. (2008) 195:157-63. doi: 10.1016/j.jneuroim.2008.01.005

48. Koch A, Zacharowski K, Boehm O, Stevens M, Lipfert P, Von Giesen $\mathrm{HJ}$, et al. Nitric oxide and pro-inflammatory cytokines correlate with pain intensity in chronic pain patients. Inflamm Res. (2007) 56:327. doi: 10.1007/s00011-007-6088-4

49. Zelenka $M$, Schäfers $M$, Sommer C. Intraneural injection of interleukin- $1 \beta$ and tumor necrosis factor-alpha into rat sciatic nerve at physiological doses induces signs of neuropathic pain. Pain. (2005) 116:257-63. doi: 10.1016/j.pain.2005.04.018

50. Wagner R, Myers RR. Endoneurial injection of TNF- $\alpha$ produces neuropathic pain behaviors. Neuroreport. (1996) 7:2897-901. doi: 10.1097/00001756-199611250-00018

51. Murata Y, Onda A, Rydevik B, Takahashi I, Takahashi K, Olmarker K. Changes in pain behavior and histologic changes caused by application of tumor necrosis factor-alpha to the dorsal root ganglion in rats. Spine (Phila Pa 1976). (2006) 31:530-5. doi: 10.1097/01.brs.0000201260.10082.23

52. Igarashi T, Kikuchi S, Shubayev V, Myers RR. Exogenous tumor necrosis factor-alpha mimics nucleus pulposus-induced neuropathology: molecular, histologic, and behavioral comparisons in rats. Spine (Phila Pa 1976). (2000) 25:2975-80. doi: 10.1097/00007632-200012010-00003

53. Homma Y, Brull SJ, Zhang JM. A comparison of chronic pain behavior following local application of tumor necrosis factor $\alpha$ to the normal and mechanically compressed lumbar ganglia in the rat. Pain. (2002) 95:23946. doi: 10.1016/S0304-3959(01)00404-3

54. Xu JT, Xin WJ, Zang Y, Wu CY, Liu XG. The role of tumor necrosis factoralpha in the neuropathic pain induced by Lumbar 5 ventral root transection in rat. Pain. (2006) 123:306-21. doi: 10.1016/j.pain.2006.03.011

55. Zheng W, Ouyang H, Zheng X, Liu S, Mata M, Fink DJ, et al. Glial TNF $\alpha$ in the spinal cord regulates neuropathic pain induced by HIV gp120 application in rats. Mol Pain. (2011) 7:40. doi: 10.1186/1744-8069-7-40

56. Sun Y, Yang M, Tang H, Ma Z, Liang Y, Li Z. The over-production of TNF- $\alpha$ via Toll-like receptor 4 in spinal dorsal horn contributes to the chronic postsurgical pain in rat. J Anesth. (2015) 29:73440. doi: 10.1007/s00540-015-2011-2

57. Wei XH, Zang Y, Wu CY, Xu JT, Xin WJ, Liu XG. Peri-sciatic administration of recombinant rat TNF- $\alpha$ induces mechanical allodynia via upregulation of TNF- $\alpha$ in dorsal root ganglia and in spinal dorsal horn: the role of NF-kappa B pathway. Exp Neurol. (2007) 205:47184. doi: 10.1016/j.expneurol.2007.03.012

58. Covey WC, Ignatowski TA, Knight PR, Spengler RN. Brainderived $\mathrm{TNF} \alpha$ : involvement in neuroplastic changes implicated in the conscious perception of persistent pain. Brain Res. (2000) 859:113-22. doi: 10.1016/S0006-8993(00)01965-X

59. Ignatowski TA, Covey WC, Knight PR, Severin CM, Nickola TJ, et al. Brain-derived TNF $\alpha$ mediates neuropathic pain. Brain Res. (1999) 841:707. doi: 10.1016/S0006-8993(99)01782-5

60. Yao PW, Wang SK, Chen SX, Xin WJ, Liu XG, Zang Y. Upregulation of tumor necrosis factor-alpha in the anterior cingulate cortex contributes to neuropathic pain and pain-associated aversion. Neurobiol Dis. (2019) 130:104456. doi: 10.1016/j.nbd.2019.04.012

61. Beattie EC, Stellwagen D, Morishita W, Bresnahan JC, Byeong KH, Von Zastrow M, et al. Control of synaptic strength by glial TNF $\alpha$. Science. (2002) 295:2282-5. doi: 10.1126/science. 1067859

62. Stellwagen D, Beattie EC, Seo JY, Malenka RC. Differential regulation of AMPA receptor and GABA receptor trafficking by tumor necrosis factor- $\alpha$. $J$ Neurosci. (2005) 25:3219-28. doi: 10.1523/JNEUROSCI.4486-04.2005

63. Wigerblad G, Huie JR, Yin HZ, Leinders M, Pritchard RA, Koehrn FJ, et al. Inflammation-induced GluA1 trafficking and membrane insertion of $\mathrm{Ca} 2+$ permeable AMPA receptors in dorsal horn neurons is dependent on spinal tumor necrosis factor, PI3 kinase and protein kinase A. Exp Neurol. (2017) 293:144-58. doi: 10.1016/j.expneurol.2017.04.004
64. Jia D, Gao GD, Liu Y, He SM, Zhang XN, Zhang YF, et al. TNF- $\alpha$ involves in altered prefrontal synaptic transmission in mice with persistent inflammatory pain. Neurosci Lett. (2007) 415:1-5. doi: 10.1016/j.neulet.2006.12.032

65. Park CK, Lü N, Xu ZZ, Liu T, Serhan CN, Ji RR. Resolving TRPV1- and TNF- $\alpha$-mediated spinal cord synaptic plasticity and inflammatory pain with neuroprotectin D1. J Neurosci. (2011) 31:15072-85. doi: 10.1523/JNEUROSCI.2443-11.2011

66. Hensellek S, Brell P, Schaible HG, Bräuer R, Segond von Banchet G. The cytokine TNF $\alpha$ increases the proportion of DRG neurones expressing the TRPV1 receptor via the TNFR1 receptor and ERK activation. Mol Cell Neurosci. (2007) 36:381-91. doi: 10.1016/j.mcn.2007.07.010

67. Stellwagen D, Malenka RC. Synaptic scaling mediated by glial TNF- $\alpha$. Nature. (2006) 440:1054-9. doi: 10.1038/nature04671

68. Steinmetz CC, Turrigiano GG. Tumor necrosis factor- $\alpha$ signaling maintains the ability of cortical synapses to express synaptic scaling. J Neurosci. (2010) 30:14685-90. doi: 10.1523/JNEUROSCI.2210-10.2010

69. Maggio N, Vlachos A. Tumor necrosis factor (TNF) modulates synaptic plasticity in a concentration-dependent manner through intracellular calcium stores. J Mol Med. (2018) 96:103947. doi: 10.1007/s00109-018-1674-1

70. Rozen T, Swidan SZ. Elevation of CSF tumor necrosis factor $\alpha$ levels in new daily persistent headache and treatment refractory chronic migraine. Headache J Head Face Pain. (2007) 47:1050-5. doi: 10.1111/j.1526-4610.2006.00722.x

71. Kraychete DC, Sakata RK, Issy AM, Bacellar O, Santos-Jesus R, Carvalho EM. Serum cytokine levels in patients with chronic low back pain due to herniated disc: analytical cross-sectional study. Sáo Paulo Med J. (2010) 128:259-62. doi: 10.1590/S1516-31802010000500003

72. Xu J, E X, Liu H, Li F, Cao Y, Tian J, et al. Tumor necrosis factor-alpha is a potential diagnostic biomarker for chronic neuropathic pain after spinal cord injury. Neurosci Lett. (2015) 595:30-4. doi: 10.1016/j.neulet.2015.04.004

73. Chen J, Song Y, Yang J, Zhang Y, Zhao P, et al. The contribution of TNF- $\alpha$ in the amygdala to anxiety in mice with persistent inflammatory pain. Neurosci Lett. (2013) 541:275-80. doi: 10.1016/j.neulet.2013.02.005

74. Miyoshi K, Obata K, Kondo T, Okamura H, Noguchi K. Interleukin18-mediated microglia/astrocyte interaction in the spinal cord enhances neuropathic pain processing after nerve injury. J Neurosci. (2008) 28:1277587. doi: 10.1523/JNEUROSCI.3512-08.2008

75. Gong Q, Lin Y, Lu Z, Xiao Z. Microglia-astrocyte cross talk through IL-18/IL-18R signaling modulates migraine-like behavior in experimental models of migraine. Neuroscience. (2020) 451:207-15. doi: 10.1016/j.neuroscience.2020.10.019

76. Luo X, Tai WL, Sun L, Pan Z, Xia Z, Chung SK, et al. Crosstalk between astrocytic CXCL12 and microglial CXCR4 contributes to the development of neuropathic pain. Mol Pain. (2016) 12:174480691663638. doi: 10.1177/1744806916636385

77. Dopp JM, Mackenzie-Graham A, Otero GC, Merrill JE. Differential expression, cytokine modulation, and specific functions of type-1 and type-2 tumor necrosis factor receptors in rat glia. J Neuroimmunol. (1997) 75:10412. doi: 10.1016/S0165-5728(97)00009-X

78. Kuno R, Wang J, Kawanokuchi J, Takeuchi H, Mizuno T, Suzumura A. Autocrine activation of microglia by tumor necrosis factor- $\alpha$. J Neuroimmunol. (2005) 162:89-96. doi: 10.1016/j.jneuroim.2005.01.015

79. Liddelow SA, Guttenplan KA, Clarke LE, Bennett FC, Bohlen CJ, Schirmer $\mathrm{L}$, et al. Neurotoxic reactive astrocytes are induced by activated microglia. Nature. (2017) 541:481-7. doi: 10.1038/nature21029

80. Kirkley KS, Popichak KA, Afzali MF, Legare ME, Tjalkens RB. Microglia amplify inflammatory activation of astrocytes in manganese neurotoxicity. J Neuroinflammation. (2017) 14:99. doi: 10.1186/s12974-017-0871-0

81. Kuno R, Yoshida Y, Nitta A, Nabeshima T, Wang J, Sonobe Y, et al. The role of TNF-alpha and its receptors in the production of NGF and GDNF by astrocytes. Brain Res. (2006) 1116:12-8. doi: 10.1016/j.brainres.2006.07.120

82. Gao Y-J, Zhang L, Samad OA, Suter MR, Yasuhiko K, Xu Z-Z, et al. JNK-Induced MCP-1 production in spinal cord astrocytes contributes to central sensitization and neuropathic pain. J Neurosci. (2009) 29:4096108. doi: 10.1523/JNEUROSCI.3623-08.2009 
83. Dérijard B, Hibi M, Wu IH, Barrett T, Su B, Deng T, et al. JNK1: a protein kinase stimulated by UV light and Ha-Ras that binds and phosphorylates the c-Jun activation domain. Cell. (1994) 76:102537. doi: 10.1016/0092-8674(94)90380-8

84. Gao Y-J, Zhang L, Ji R-R. Spinal injection of TNF- $\alpha$-activated astrocytes produces persistent pain symptom mechanical allodynia by releasing monocyte chemoattractant protein-1. Glia. (2010) 58:1871-80. doi: 10.1002/glia.21056

85. Gosselin RD, Varela C, Banisadr G, Mechighel P, Rostene W, Kitabgi P, et al. Constitutive expression of CCR2 chemokine receptor and inhibition by MCP-1/CCL2 of GABA-induced currents in spinal cord neurones. $J$ Neurochem. (2005) 95:1023-34. doi: 10.1111/j.1471-4159.2005.03431.x

86. Sun JH, Yang B, Donnelly DF, Ma C, LaMotte RH. MCP-1 Enhances excitability of nociceptive neurons in chronically compressed dorsal root ganglia. J Neurophysiol. (2006) 96:2189-99. doi: 10.1152/jn.00222.2006

87. White FA, Sun J, Waters SM, Ma C, Ren D, Ripsch M, et al. Excitatory monocyte chemoattractant protein-1 signaling is up-regulated in sensory neurons after chronic compression of the dorsal root ganglion. Proc Natl Acad Sci USA. (2005) 102:14092-7. doi: 10.1073/pnas.0503496102

88. Hu JH, Wu MY, Tao M, Yang JP. Changes in protein expression and distribution of spinal CCR2 in a rat model of bone cancer pain. Brain Res. (2013) 1509:1-7. doi: 10.1016/j.brainres.2013.03.002

89. Zhang ZJ, Dong YL, Lu Y, Cao S, Zhao ZQ, Gao YJ. Chemokine CCL2 and its receptor CCR2 in the medullary dorsal horn are involved in trigeminal neuropathic pain. J Neuroinflammation. (2012) 9:569. doi: 10.1186/1742-2094-9-136

90. Wu XB, Jing PB, Zhang ZJ, Cao DL, Gao MH, Jiang $\mathrm{BC}$, et al. Chemokine receptor CCR2 contributes to neuropathic pain and the associated depression via increasing NR2B-mediated currents in both D1 and D2 dopamine receptor-containing medium spiny neurons in the nucleus accumbens shell. Neuropsychopharmacology. (2018) 43:232030. doi: 10.1038/s41386-018-0115-8

91. Kwon M, Altin M, Duenas H, Alev L. The role of descending inhibitory pathways on chronic pain modulation and clinical implications. Pain Pract. (2014) 14:656-67. doi: 10.1111/papr.12145

92. Murphy G, Nagase H. Progress in matrix metalloproteinase research. Mol Aspects Med. (2009) 29:290-308. doi: 10.1016/j.mam.2008.05.002

93. Akhter N, Nix M, Abdul Y, Singh S, Husain S. Delta-opioid receptors attenuate TNF- $\alpha$-induced MMP-2 secretion from human $\mathrm{ONH}$ astrocytes. Investig Ophthalmol Vis Sci. (2013) 54:6605-11. doi: 10.1167/iovs.13-12196

94. Wang LT, Wang F, Ke ZF, Wang R, Wang YF, Huang LL. Astrocyte elevated gene-1 (AEG-1) promotes osteosarcoma cell invasion through the JNK/c-Jun/MMP-2 pathway. Biochem Biophys Res Commun. (2014) 452:933-9. doi: 10.1016/j.bbrc.2014.09.009

95. Wu C-Y, Hsieh H-L, Sun C-C, Yang C-M. IL-1 $\beta$ induces MMP-9 expression via a $\mathrm{Ca}^{2+}$-dependent CaMKII/JNK/c-JUN cascade in rat brain astrocytes. Glia. (2009) 57:1775-89. doi: 10.1002/glia.20890

96. Bozdagi O, Nagy V, Kwei KT, Huntley GW. In vivo roles for matrix metalloproteinase-9 in mature hippocampal synaptic physiology and plasticity. J Neurophysiol. (2007) 98:334-44. doi: 10.1152/jn.00202.2007

97. Wang X-b, Bozdagi O, Nikitczuk JS, Zu WZ, Zhou Q, Huntley GW. Extracellular proteolysis by matrix metalloproteinase-9 drives dendritic spine enlargement and long-term potentiation coordinately. Proc Natl Acad Sci USA. (2008) 105:19520-5. doi: 10.1073/pnas.0807248105

98. Sandhir R, Gregory E, He YY, Berman NEJ. Upregulation of inflammatory mediators in a model of chronic pain after spinal cord injury. Neurochem Res. (2011) 36:856-62. doi: 10.1007/s11064-011-0414-5

99. Kawasaki Y, Xu ZZ, Wang X, Park JY, Zhuang ZY, Tan PH, et al. Distinct roles of matrix metalloproteases in the early- and late-phase development of neuropathic pain. Nat Med. (2008) 14:331-6. doi: 10.1038/nm1723

100. Tian G, Luo X, Tang C, Cheng X, Chung SK, Xia Z, et al. Astrocyte contributes to pain development via MMP2-JNK1/2 signaling in a mouse model of complex regional pain syndrome. Life Sci. (2017) 170:6471. doi: 10.1016/j.lfs.2016.11.030

101. Zhuang ZY, Wen YR, Zhang DR, Borsello T, Bonny C, Strichartz $\mathrm{GR}$, et al. A peptide c-Jun N-terminal kinase (JNK) inhibitor blocks mechanical allodynia after spinal nerve ligation: respective roles of JNK activation in primary sensory neurons and spinal astrocytes for neuropathic pain development and maintenance. J Neurosci. (2006) 26:355160. doi: 10.1523/JNEUROSCI.5290-05.2006

102. Liao WT, Tseng CC, Wu CH, Lin CR. Early high-frequency spinal cord stimulation treatment inhibited the activation of spinal mitogen-activated protein kinases and ameliorated spared nerve injury-induced neuropathic pain in rats. Neurosci Lett. (2020) 721:134763. doi: 10.1016/j.neulet.2020.134763

103. Gao YJ, Xu ZZ, Liu YC, Wen YR, Decosterd I, Ji RR. The c-Jun Nterminal kinase 1 (JNK1) in spinal astrocytes is required for the maintenance of bilateral mechanical allodynia under a persistent inflammatory pain condition. Pain. (2010) 148:309-19. doi: 10.1016/j.pain.2009.11.017

104. Pasti L, Volterra A, Pozzan T, Carmignoto G. Intracellular calcium oscillations in astrocytes: a highly plastic, bidirectional form of communication between neurons and astrocytes in situ. J Neurosci. (1997) 17:7817-30. doi: 10.1523/JNEUROSCI.17-20-07817.1997

105. Porter JT, McCarthy KD. Hippocampal astrocytes in situ respond to glutamate released from synaptic terminals. J Neurosci. (1996) 16:507381. doi: 10.1523/JNEUROSCI.16-16-05073.1996

106. Covelo A, Araque A. Neuronal activity determines distinct gliotransmitter release from a single astrocyte. Elife. (2018) 7:e32237. doi: 10.7554/eLife.32237

107. Durkee CA, Covelo A, Lines J, Kofuji P, Aguilar J, Araque A. G i/o proteincoupled receptors inhibit neurons but activate astrocytes and stimulate gliotransmission. Glia. (2019) 67:1076-93. doi: 10.1002/glia.23589

108. Gaidin SG, Zinchenko VP, Sergeev AI, Teplov IY, Mal'tseva VN, Kosenkov AM. Activation of alpha-2 adrenergic receptors stimulates GABA release by astrocytes. Glia. (2020) 68:1114-30. doi: 10.1002/glia.23763

109. Araque A, Carmignoto G, Haydon PG, Oliet SHR, Robitaille R, Volterra A. Gliotransmitters travel in time and space. Neuron. (2014) 81:72839. doi: 10.1016/j.neuron.2014.02.007

110. Savtchouk I, Volterra A. Gliotransmission: beyond black-and-white. J Neurosci. (2018) 38:14-25. doi: 10.1523/JNEUROSCI.0017-17.2017

111. Fiacco TA, McCarthy KD. Multiple lines of evidence indicate that gliotransmission does not occur under physiological conditions. J Neurosci. (2018) 38:3-13. doi: 10.1523/JNEUROSCI.0016-17.2017

112. Bezzi P, Domercq M, Brambilla L, Galli R, Schols D, De Clercq $\mathrm{E}$, et al. CXCR4-activated astrocyte glutamate release via TNFa: amplification by microglia triggers neurotoxicity. Nat Neurosci. (2001) 4:702-10. doi: 10.1038/89490

113. Pascual O, Achour SB, Rostaing P, Triller A, Bessis A. Microglia activation triggers astrocyte-mediated modulation of excitatory neurotransmission. Proc Natl Acad Sci USA. (2012) 109:E197-205. doi: 10.1073/pnas.1111098109

114. Li S, Uno Y, Rudolph U, Cobb J, Liu J, Anderson T, et al. Astrocytes in primary cultures express serine racemase, synthesize $\mathrm{D}$-serine and acquire A1 reactive astrocyte features. Biochem Pharmacol. (2018) 151:24551. doi: 10.1016/j.bcp.2017.12.023

115. Balu DT, Pantazopoulos H, Huang CCY, Muszynski K, Harvey TL, Uno Y, et al. Neurotoxic astrocytes express the D-serine synthesizing enzyme, serine racemase, in Alzheimer's disease. Neurobiol Dis. (2019) 130:104511. doi: 10.1016/j.nbd.2019.104511

116. Perez EJ, Tapanes SA, Loris ZB, Balu DT, Sick TJ, Coyle JT, et al. Enhanced astrocytic d-serine underlies synaptic damage after traumatic brain injury. $J$ Clin Invest. (2017) 127:3114-25. doi: 10.1172/JCI92300

117. Domercq M, Brambilla L, Pilati E, Marchaland J, Volterra A, Bezzi P. P2Y1 receptor-evoked glutamate exocytosis from astrocytes: control by tumor necrosis factor- $\alpha$ and prostaglandins. J Biol Chem. (2006) 281:3068496. doi: 10.1074/jbc.M606429200

118. Santello M, Bezzi P, Volterra A. TNF $\alpha$ Controls glutamatergic gliotransmission in the hippocampal dentate gyrus. Neuron. (2011) 69:988-1001. doi: 10.1016/j.neuron.2011.02.003

119. Mothet JP, Parent AT, Wolosker H, Brady RO, Linden DJ, Ferris CD, et al. D-serine is an endogenous ligand for the glycine site of the $\mathrm{N}$ methyl-D-aspartate receptor. Proc Natl Acad Sci USA. (2000) 97:492631. doi: 10.1073/pnas.97.9.4926

120. Wolosker H, Blackshaw S, Snyder SH. Serine racemase: a glial enzyme synthesizing D-serine to regulate glutamate-N-methylD-aspartate neurotransmission. Proc Natl Acad Sci USA. (1999) 96:13409-14. doi: 10.1073/pnas.96.23.13409 
121. Miya K, Inoue R, Takata Y, Abe M, Natsume R, Sakimura K, et al. Serine racemase is predominantly localized in neurons in mouse brain. J Comp Neurol. (2008) 510:641-54. doi: 10.1002/cne.21822

122. Miraucourt LS, Peirs C, Dallel R, Voisin DL. Glycine inhibitory dysfunction turns touch into pain through astrocyte-derived d-serine. Pain. (2011) 152:1340-8. doi: 10.1016/j.pain.2011.02.021

123. Dieb W, Hafidi A. Astrocytes are involved in trigeminal dynamic mechanical allodynia: potential role of D-serine. J Dent Res. (2013) 92:80813. doi: $10.1177 / 0022034513498898$

124. Lefèvre Y, Amadio A, Vincent P, Descheemaeker A, Oliet SHR, Dallel R, et al. Neuropathic pain depends upon d-serine coactivation of spinal NMDA receptors in rats. Neurosci Lett. (2015) 603:42-7. doi: 10.1016/j.neulet.2015.07.010

125. Choi SR, Roh DH, Yoon SY, Choi HS, Kang SY, Han HJ, et al. Astrocyte Dserine modulates the activation of neuronal NOS leading to the development of mechanical allodynia in peripheral neuropathy. Mol Pain. (2019) 15:174480691984304. doi: 10.1177/1744806919843046

126. Kartvelishvily E, Shleper M, Balan L, Dumin E, Wolosker H. Neuron-derived $\mathrm{D}$-serine release provides a novel means to activate N-methyl-D-aspartate receptors. J Biol Chem. (2006) 281:14151-62. doi: 10.1074/jbc.M512927200

127. Burnstock G. Pathophysiology and therapeutic potential of purinergic signaling. Pharmacol Rev. (2006) 58:58-86. doi: 10.1124/pr.58.1.5

128. Gu JG, MacDermott AB. Activation of ATP P2X receptors elicits glutamate release from sensory neuron synapses. Nature. (1997) 389:74953. doi: $10.1038 / 39639$

129. Rodrigues RJ, Almeida T, Richardson PJ, Oliveira CR, Cunha RA. Dual presynaptic control by ATP of glutamate release via facilitatory $\mathrm{P} 2 \mathrm{X} 1, \mathrm{P} 2 \mathrm{X} 2 / 3$, and $\mathrm{P} 2 \mathrm{X} 3$ and inhibitory $\mathrm{P} 2 \mathrm{Y} 1, \mathrm{P} 2 \mathrm{Y} 2$, and/or P2Y4 receptors in the rat hippocampus. J Neurosci. (2005) 25:6286-95. doi: 10.1523/JNEUROSCI.0628-05.2005

130. Bardoni R. ATP $\mathrm{P}(2 \mathrm{X})$ receptors mediate fast synaptic transmission in the dorsal horn of the rat spinal cord. J Neurosci. (1997) 17:5297304. doi: 10.1523/JNEUROSCI.17-14-05297.1997

131. Mori M, Heuss C, Gähwiler BH, Gerber U. Fast synaptic transmission mediated by $\mathrm{P} 2 \mathrm{X}$ receptors in CA3 pyramidal cells of rat hippocampal slice cultures. $J$ Physiol. (2001) 535:115-23. doi: 10.1111/j.1469-7793.2001.t01-1-00115.x

132. Pankratov Y, Lalo U, Krishtal O, Verkhratsky A. Ionotropic P2X purinoreceptors mediate synaptic transmission in rat pyramidal neurones of layer II/III of somato-sensory cortex. J Physiol. (2002) 542:52936. doi: 10.1113/jphysiol.2002.021956

133. Mendoza-Fernandez V, Andrew RD, Barajas-López C. ATP inhibits glutamate synaptic release by acting at $\mathrm{P} 2 \mathrm{Y}$ receptors in pyramidal neurons of hippocampal slices. J Pharmacol Exp Ther. (2000) 293:172-179.

134. Zhang P-A, Zhu HY, Xu QY, Du WJ, Hu S, Xu GY. Sensitization of P2X3 receptors in insular cortex contributes to visceral pain of adult rats with neonatal maternal deprivation. Mol Pain. (2018) 14:174480691876473. doi: 10.1177/1744806918764731

135. Zhang P-A, Xu Q-Y, Xue L, Zheng H, Yan J, Xiao Y, et al. Neonatal maternal deprivation enhances presynaptic $\mathrm{P} 2 \mathrm{X} 7$ receptor transmission in insular cortex in an adult rat model of visceral hypersensitivity. CNS Neurosci Ther. (2017) 23:145-54. doi: 10.1111/cns.12663

136. Cui J, He W, Yi B, Zhao H, Lu K, Ruan H, et al. MTOR pathway is involved in ADP-evoked astrocyte activation and ATP release in the spinal dorsal horn in a rat neuropathic pain model. Neuroscience. (2014) 275:395403. doi: 10.1016/j.neuroscience.2014.06.030

137. Koyanagi S, Kusunose N, Taniguchi M, Akamine T, Kanado Y, Ozono Y, et al. Glucocorticoid regulation of ATP release from spinal astrocytes underlies diurnal exacerbation of neuropathic mechanical allodynia. Nat Commun. (2016) 7:1-13. doi: 10.1038/ncomms13102

138. Drago F, Lombardi M, Prada I, Gabrielli M, Joshi P, Cojoc D, et al. ATP modifies the proteome of extracellular vesicles released by microglia and influences their action on astrocytes. Front Pharmacol. (2017) 8:910. doi: 10.3389/fphar.2017.00910

139. Bianco F, Pravettoni E, Colombo A, Schenk U, Möller T, Matteoli M, et al. Astrocyte-derived ATP induces vesicle shedding and IL-1 $\beta$ release from microglia. J Immunol. (2005) 174:7268-77. doi: 10.4049/jimmunol.174.11.7268
140. Kobayashi K, Takahashi E, Miyagawa Y, Yamanaka H, Noguchi K. Induction of the P2X7 receptor in spinal microglia in a neuropathic pain model. Neurosci Lett. (2011) 504:57-61. doi: 10.1016/j.neulet.2011.08.058

141. Ulmann L, Hatcher JP, Hughes JP, Chaumont S, Green PJ, Conquet F, et al. Up-regulation of $\mathrm{P} 2 \mathrm{X} 4$ receptors in spinal microglia after peripheral nerve injury mediates BDNF release and neuropathic pain. J Neurosci. (2008) 28:11263-8. doi: 10.1523/JNEUROSCI.2308-08.2008

142. Trang T, Beggs S, Salter MW. ATP receptors gate microglia signaling in neuropathic pain. Exp Neurol. (2012) 234:35461. doi: 10.1016/j.expneurol.2011.11.012

143. McKenna MC. The glutamate-glutamine cycle is not stoichiometric: fates of glutamate in brain. J Neurosci Res. (2007) 85:3347-58. doi: 10.1002/jnr.21444

144. Zunhammer M, Schweizer LM, Witte V, Harris RE, Bingel U, SchmidtWilcke T. Combined glutamate and glutamine levels in pain-processing brain regions are associated with individual pain sensitivity. Pain. (2016) 157:2248-56. doi: 10.1097/j.pain.0000000000000634

145. Mullins PG, Rowland LM, Jung RE, Sibbitt WL. A novel technique to study the brain's response to pain: proton magnetic resonance spectroscopy. Neuroimage. (2005) 26:642-46. doi: 10.1016/j.neuroimage.2005.02.001

146. Ito T, Tanaka-Mizuno S, Iwashita N, Tooyama I, Shiino A, Miura K, et al. Proton magnetic resonance spectroscopy assessment of metabolite status of the anterior cingulate cortex in chronic pain patients and healthy controls. $J$ Pain Res. (2017) 10:287-93. doi: 10.2147/JPR.S123403

147. Bathel A, Schweizer L, Stude P, Glaubitz B, Wulms N, Delice S, et al. Increased thalamic glutamate/glutamine levels in migraineurs. J Headache Pain. (2018) 19:55. doi: 10.1186/s10194-018-0885-8

148. Valdés M, Collado A, Bargalló N, Vázquez M, Rami L, Gómez E, et al. Increased glutamate/glutamine compounds in the brains of patients with fibromyalgia: a magnetic resonance spectroscopy study. Arthritis Rheum. (2010) 62:1829-36. doi: 10.1002/art.27430

149. Lehre KP, Levy LM, Ottersen OP, Storm-Mathisen J, Danbolt NC. Differential expression of two glial glutamate transporters in the rat brain: quantitative and lmmunocytochemical observations. J Neurosci. (1995) 15(3 Pt 1):183553. doi: 10.1523/JNEUROSCI.15-03-01835.1995

150. Wang W, Wang W, Wang Y, Huang J, Wu S, Li Y-Q. Temporal changes of astrocyte activation and glutamate transporter-1 expression in the spinal cord after spinal nerve ligation-induced neuropathic pain. Anat Rec Adv Integr Anat Evol Biol. (2008) 291:513-18. doi: 10.1002/ar.20673

151. Sung B, Lim G, Mao J. Altered expression and uptake activity of spinal glutamate transporters after nerve injury contribute to the pathogenesis of neuropathic pain in rats. J Neurosci. (2003) 23:2899910. doi: 10.1523/JNEUROSCI.23-07-02899.2003

152. Xin W-J, Weng H-R, Dougherty PM. Plasticity in expression of the glutamate transporters GLT-1 and GLAST in spinal dorsal horn glial cells following partial sciatic nerve ligation. Mol Pain. (2009) 5:15. doi: 10.1186/1744-8069-5-15

153. Putatunda R, Hala TJ, Chin J, Lepore AC. Chronic at-level thermal hyperalgesia following rat cervical contusion spinal cord injury is accompanied by neuronal and astrocyte activation and loss of the astrocyte glutamate transporter, GLT1, in superficial dorsal horn. Brain Res. (2014) 1581:64-79. doi: 10.1016/j.brainres.2014.05.003

154. Maeda S, Kawamoto A, Yatani Y, Shirakawa H, Nakagawa T, Kaneko S. Gene transfer of GLT-1, a glial glutamate transporter, into the spinal cord by recombinant adenovirus attenuates inflammatory and neuropathic pain in rats. Mol Pain. (2008) 4:1-13. doi: 10.1186/1744-8069-4-65

155. Falnikar A, Hala TJ, Poulsen DJ, Lepore AC. GLT1 overexpression reverses established neuropathic pain-related behavior and attenuates chronic dorsal horn neuron activation following cervical spinal cord injury. Glia. (2016) 64:396-406. doi: 10.1002/glia.22936

156. Tsuboi Y, Iwata K, Dostrovsky JO, Chiang CY, Sessle BJ, Hu JW. Modulation of astroglial glutamine synthetase activity affects nociceptive behaviour and central sensitization of medullary dorsal horn nociceptive neurons in a rat model of chronic pulpitis. Eur J Neurosci. (2011) 34:292302. doi: 10.1111/j.1460-9568.2011.07747.x

157. Yang KY, Mun JH, Park KD, Kim MJ, Ju JS, Kim ST, et al. Blockade of spinal glutamate recycling produces paradoxical antinociception in rats with orofacial inflammatory pain. Prog Neuropsychopharmacol Biol Psychiatry. (2015) 57:100-9. doi: 10.1016/j.pnpbp.2014.10.011 
158. López-Redondo F, Nakajima K, Honda S, Kohsaka S. Glutamate transporter GLT-1 is highly expressed in activated microglia following facial nerve axotomy. Mol Brain Res. (2000) 76:42935. doi: 10.1016/S0169-328X(00)00022-X

159. Cataldo AM, Broadwell RD. Cytochemical identification of cerebral glycogen and glucose-6-phosphatase activity under normal and experimental conditions: I. Neurons and glia. J Electron Microsc Tech. (1986) 3:41337. doi: 10.1002/jemt.1060030406

160. Dringen R, Gebhardt R, Hamprecht B. Glycogen in astrocytes: possible function as lactate supply for neighboring cells. Brain Res. (1993) 623:20814. doi: 10.1016/0006-8993(93)91429-V

161. Walz W, Mukerji S. Lactate production and release in cultured astrocytes. Neurosci Lett. (1988) 86:296-300. doi: 10.1016/0304-3940(88)90499-5

162. Walz W, Mukerji S. Lactate release from cultured astrocytes and neurons: a comparison. Glia. (1988) 1:366-370. doi: 10.1002/glia.440010603

163. Rogatzki MJ, Ferguson BS, Goodwin ML, Gladden LB. Lactate is always the end product of glycolysis. Front Neurosci. (2015) 9:22. doi: 10.3389/fnins.2015.00022

164. Oksanen M, Petersen AJ, Naumenko N, Puttonen K, Lehtonen Š, Gubert Olivé M, et al. PSEN1 mutant iPSC-derived model reveals severe astrocyte pathology in alzheimer's disease. Stem Cell Rep. (2017) 9:188597. doi: 10.1016/j.stemcr.2017.10.016

165. Zhang M, Cheng X, Dang R, Zhang W, Zhang J, Yao Z. Lactate deficit in an alzheimer disease mouse model: the relationship with neuronal damage. $J$ Neuropathol Exp Neurol. (2018) 77:1163-76. doi: 10.1093/jnen/nly102

166. Lu W, Huang J, Sun S, Huang S, Gan S, Xu J, et al. Changes in lactate content and monocarboxylate transporter 2 expression in $\mathrm{A} \beta 25$ 35-treated rat model of Alzheimer's disease. Neurol Sci. (2015) 36:87176. doi: 10.1007/s10072-015-2087-3

167. Liu B, Niu L, Shen MZ, Gao L, Wang C, Li J, et al. Decreased astroglial monocarboxylate transporter 4 expression in temporal lobe epilepsy. Mol Neurobiol. (2014) 50:327-38. doi: 10.1007/s12035-013-8619-z

168. Zeis T, Allaman I, Gentner M, Schroder K, Tschopp J, Magistretti PJ, et al. Metabolic gene expression changes in astrocytes in Multiple Sclerosis cerebral cortex are indicative of immune-mediated signaling. Brain Behav Immun. (2015) 48:313-25. doi: 10.1016/j.bbi.2015.04.013

169. Aasly J, Gårseth M, Sonnewald U, Zwart J-A, White LR, Unsgård G. Cerebrospinal fluid lactate and glutamine are reduced in multiple sclerosis. Acta Neurol Scand. (1997) 95:9-12. doi: 10.1111/j.1600-0404.1997.tb00060.x

170. Ernst J, Hock A, Henning A, Seifritz E, Boeker H, Grimm S. Increased pregenual anterior cingulate glucose and lactate concentrations in major depressive disorder. Mol Psychiatry. (2017) 22:113-9. doi: $10.1038 / \mathrm{mp} .2016 .73$

171. Bélanger M, Allaman I, Magistretti PJ. Differential effects of pro- and anti-inflammatory cytokines alone or in combinations on the metabolic profile of astrocytes. J Neurochem. (2011) 116:564-76. doi: 10.1111/j.1471-4159.2010.07135.x

172. Bushong EA, Martone ME, Jones YZ, Ellisman MH. Protoplasmic astrocytes in CA1 stratum radiatum occupy separate anatomical domains. J Neurosci. (2002) 22:183-92. doi: 10.1523/JNEUROSCI.22-01-00183.2002

173. Morgello S, Uson RR, Schwartz EJ, Haber RS. The human blood-brain barrier glucose transporter (GLUT1) is a glucose transporter of gray matter astrocytes. Glia. (1995) 14:43-54. doi: 10.1002/glia.440140107

174. Pellegri G, Rossier C, Magistretti PJ, Martin JL. Cloning, localization and induction of mouse brain glycogen synthase. Mol Brain Res. (1996) 38:1919. doi: 10.1016/0169-328X(95)00305-C

175. Inoue $\mathrm{N}$, Matsukado $\mathrm{Y}$, Goto S, Miyamoto E. Localization of glycogen synthase in brain. J Neurochem. (1988) 50:4005. doi: 10.1111/j.1471-4159.1988.tb02926.x

176. Pellerin L, Magistretti PJ. Glutamate uptake into astrocytes stimulates aerobic glycolysis: a mechanism coupling neuronal activity to glucose utilization. Proc Natl Acad Sci USA. (1994) 91:10625-9. doi: 10.1073/pnas.91.22.10625

177. Bittner CX, Valdebenito R, Ruminot I, Loaiza A, Larenas V, Sotelo-Hitschfeld $\mathrm{T}$, et al. Fast and reversible stimulation of astrocytic glycolysis by $\mathrm{K}+$ and a delayed and persistent effect of glutamate. J Neurosci. (2011) 31:470913. doi: 10.1523/JNEUROSCI.5311-10.2011
178. Pellerin L, Pellegri G, Bittar PG, Charnay Y, Bouras C, Martin JL, et al. Evidence supporting the existence of an activity-dependent astrocyte-neuron lactate shuttle. Dev Neurosci. (1998) 20:291-9. doi: 10.1159/000017324

179. Suzuki A, Stern SA, Bozdagi O, Huntley GW, Walker RH, Magistretti PJ, et al. Astrocyte-neuron lactate transport is required for long-term memory formation. Cell. (2011) 144:810-23. doi: 10.1016/j.cell.2011.02.018

180. Descalzi G, Gao V, Steinman MQ, Suzuki A, Alberini CM. Lactate from astrocytes fuels learning-induced mRNA translation in excitatory and inhibitory neurons. Commun Biol. (2019) 2:247. doi: 10.1038/s42003-019-0495-2

181. Netzahualcoyotzi C, Pellerin L. Neuronal and astroglial monocarboxylate transporters play key but distinct roles in hippocampusdependent learning and memory formation. Prog Neurobiol. (2020) 194:101888. doi: 10.1016/j.pneurobio.2020.101888

182. Zhang Y, Xue Y, Meng S, Luo Y, Liang J, Li J, et al. Inhibition of lactate transport erases drug memory and prevents drug relapse. Biol Psychiatry. (2016) 79:928-39. doi: 10.1016/j.biopsych.2015.07.007

183. Boury-Jamot B, Carrard A, Martin JL, Halfon O, Magistretti PJ, et al. Disrupting astrocyte-neuron lactate transfer persistently reduces conditioned responses to cocaine. Mol Psychiatry. (2016) 21:10706. doi: $10.1038 / \mathrm{mp} .2015 .157$

184. Ji RR, Rupp F. Phosphorylation of transcription factor CREB in rat spinal cord after formalin-induced hyperalgesia: relationship to c-fos induction. $J$ Neurosci. (1997) 17:1776-85. doi: 10.1523/JNEUROSCI.17-05-01776.1997

185. Wei F, Qiu CS, Kim SJ, Muglia L, Maas JW, Pineda VV, et al. Genetic elimination of behavioral sensitization in mice lacking calmodulin-stimulated adenylyl cyclases. Neuron. (2002) 36:713-26. doi: 10.1016/S0896-6273(02)01019-X

186. Descalzi G, Fukushima H, Suzuki A, Kida S, Zhuo M. Genetic enhancement of neuropathic and inflammatory pain by forebrain upregulation of CREBmediated transcription. Mol Pain. (2012) 8:90. doi: 10.1186/1744-8069-8-90

187. He JH, Yu L, Wang ZY, Wang Q, Cao JL, Gu LB. Inhibition of monocarboxylate transporter 1 in spinal cord horn significantly reverses chronic inflammatory pain. J Pain Res. (2019) 12:298190. doi: 10.2147/JPR.S219359

188. Miletic G, Pankratz MT, Miletic V. Increases in the phosphorylation of cyclic AMP response element binding protein (CREB) and decreases in the content of calcineurin accompany thermal hyperalgesia following chronic constriction injury in rats. Pain. (2002) 99:493-500. doi: 10.1016/S0304-3959(02)00242-7

189. Song X, Cao J, Xu Y, He J, Zhang L, Zeng Y. Activation of ERK/CREB pathway in spinal cord contributes to chronic constrictive injuryinduced neuropathic pain in rats1. Acta Pharmacol Sin. (2005) 26:78998. doi: 10.1111/j.1745-7254.2005.00123.x

190. Yao C-Y, Weng Z-L, Zhang J-C, Feng T, Lin Y, Yao S. Interleukin$17 \mathrm{~A}$ Acts to maintain neuropathic pain through activation of CaMKII/CREB signaling in spinal neurons. Mol Neurobiol. (2016) 53:3914-26. doi: 10.1007/s12035-015-9322-Z

191. Crown ED, Ye Z, Johnson KM, Xu GY, McAdoo DJ, Westlund $\mathrm{KN}$, Hulsebosch CE. Upregulation of the phosphorylated form of CREB in spinothalamic tract cells following spinal cord injury: relation to central neuropathic pain. Neurosci Lett. (2005) 384:139-44. doi: 10.1016/j.neulet.2005.04.066

192. Hang LH, Yang JP, Shao DH, Chen Z, Wang H. Involvement of spinal PKA/CREB signaling pathway in the development of bone cancer pain. Pharmacol Rep. (2013) 65:710-6. doi: 10.1016/S1734-1140(13)71049-1

193. Tolou-Dabbaghian B, Delphi L, Rezayof A. Blockade of NMDA receptors and nitric oxide synthesis potentiated morphine-induced anti-allodynia via attenuating pain-related amygdala pCREB/CREB signaling pathway. J Pain. (2019) 20:885-97. doi: 10.1016/j.jpain.2019.01.329

194. Wei F, Zhuo M. Activation of erk in the anterior cingulate cortex during the induction and expression of chronic pain. Mol Pain. (2008) 4:28. doi: 10.1186/1744-8069-4-28

195. Shao XM, Sun J, Jiang YL, Liu BY, Shen Z, Fang F, et al. Inhibition of the cAMP/PKA/CREB pathway contributes to the analgesic effects of electroacupuncture in the anterior cingulate cortex in a rat pain memory model. Neural Plast. (2016) 2016:5320641. doi: 10.1155/2016/5320641 
196. Miyamoto K, Ishikura K ichiro, Kume K, Ohsawa M. Astrocyte-neuron lactate shuttle sensitizes nociceptive transmission in the spinal cord. Glia. (2019) 67:27-36. doi: 10.1002/glia.23474

197. Fujiwara A, Nakao K, Ueno T, Matsumura S, Ito S, Minami T. Stiripentol alleviates neuropathic pain in L5 spinal nerve-transected mice. J Anesth. (2020) 34:373-81. doi: 10.1007/s00540-020-02762-2

198. Wei X, Jin X-H, Meng X-W, Hua J, Ji F-H, Wang L-N, et al. Platelet-rich plasma improves chronic inflammatory pain by inhibiting PKM2-mediated aerobic glycolysis in astrocytes. Ann Transl Med. (2020) 8:1456. doi: 10.21037/atm-20-6502

199. Wang B, Liu S, Fan B, Xu X, Chen Y, Lu R, et al. PKM2 is involved in neuropathic pain by regulating ERK and STAT3 activation in rat spinal cord. J Headache Pain. (2018) 19:7. doi: 10.1186/s10194-018-0836-4

200. Dong G, Mao Q, Xia W, Xu Y, Wang J, Xu L, et al. PKM2 and cancer: the function of PKM2 beyond glycolysis (Review). Oncol Lett. (2016) 11:19806. doi: 10.3892/ol.2016.4168

201. Yang J, Ruchti E, Petit JM, Jourdain P, Grenningloh G, Allaman I,et al. Lactate promotes plasticity gene expression by potentiating NMDA signaling in neurons. Proc Natl Acad Sci USA. (2014) 111:1222833. doi: 10.1073/pnas.1322912111

202. Lauritzen KH, Morland C, Puchades M, Holm-Hansen S, Hagelin EM, Lauritzen F, et al. Lactate receptor sites link neurotransmission, neurovascular coupling, and brain energy metabolism. Cereb Cortex. (2014) 24:2784-95. doi: 10.1093/cercor/bht136

203. Abrantes H de C, Briquet M, Schmuziger C, Restivo L, Puyal J, Rosenberg $\mathrm{N}$, et al. The lactate receptor HCAR1 modulates neuronal network activity through the activation of $\mathrm{G} \alpha$ and G $\beta \gamma$ subunits. J Neurosci. (2019) 39:442233. doi: 10.1523/JNEUROSCI.2092-18.2019

204. Herrera-López G, Galván EJ. Modulation of hippocampal excitability via the hydroxycarboxylic acid receptor 1. Hippocampus. (2018) 28:55767. doi: 10.1002/hipo. 22958

205. Herrera-López G, Griego E, Galván EJ. Lactate induces synapse-specific potentiation on CA3 pyramidal cells of rat hippocampus. PLOS ONE. (2020) 15:e024230. doi: 10.1371/journal.pone.0242309

206. Tang F, Lane S, Korsak A, Paton JFR, Gourine AV, Kasparov S, et al. Lactatemediated glia-neuronal signalling in the mammalian brain. Nat Commun. (2014) 5:3284. doi: 10.1038/ncomms4993

207. Mosienko V, Rasooli-Nejad S, Kishi K, De Both M, Jane D, Huentelman M, et al. Putative receptors underpinning l-lactate signalling in locus coeruleus. Neuroglia. (2018) 1:365-80. doi: 10.3390/neuroglia1020025

208. Harun-Or-Rashid M, Inman DM. Reduced AMPK activation and increased HCAR activation drive anti-inflammatory response and neuroprotection in glaucoma. J Neuroinflammation. (2018) 15:313. doi: 10.1186/s12974-018-1346-7

209. Ma K, Ding X, Song Q, Han Z, Yao H, Ding J, et al. Lactate enhances Arc/arg3.1 expression through hydroxycarboxylic acid receptor $1-\beta$-arrestin2 pathway in astrocytes. Neuropharmacology. (2020) 171:108084. doi: 10.1016/j.neuropharm.2020.108084

210. McLennan GP, Kiss A, Miyatake M, Belcheva MM, Chambers KT, Pozek $J$, et al. Kappa opioids promote the proliferation of astrocytes via G $\beta \gamma$ and $\beta$-arrestin 2-dependent MAPK-mediated pathways. J Neurochem. (2008) 107:1753-65. doi: 10.1111/j.1471-4159.2008.05745.x

211. Bruchas MR, Macey TA, Lowe JD, Chavkin C. Kappa opioid receptor activation of p38 MAPK is GRK3- and arrestin-dependent in neurons and astrocytes. J Biol Chem. (2006) 281:18081-9. doi: 10.1074/jbc.M513640200

212. Xu M, Bruchas MR, Ippolito DL, Gendron L, Chavkin C. Sciatic nerve ligation-induced proliferation of spinal cord astrocytes is mediated by $\kappa$ opioid activation of p38 mitogen-activated protein kinase. J Neurosci. (2007) 27:2570-81. doi: 10.1523/JNEUROSCI.3728-06.2007

213. Vardjan N, Chowdhury HH, Horvat A, Velebit J, Malnar M, Muhič $\mathrm{M}$, et al. Enhancement of astroglial aerobic glycolysis by extracellular lactate-mediated increase in cAMP. Front Mol Neurosci. (2018) 11:148. doi: 10.3389/fnmol.2018.00148

214. Pahan K, Namboodiri AMS, Sheikh FG, Smith BT, Singh I. Increasing cAMP attenuates induction of inducible nitric-oxide synthase in rat primary astrocytes. J Biol Chem. (1997) 272:7786-91. doi: 10.1074/jbc.272.12.7786

215. Hsiao H-Y, Mak O-T, Yang C-S, Liu Y-P, Fang K-M, Tzeng S-F. TNF- $\alpha /$ IFN$\gamma$-induced iNOS expression increased by prostaglandin E2 in rat primary astrocytes via EP2-evoked cAMP/PKA and intracellular calcium signaling. Glia. (2007) 55:214-23. doi: 10.1002/glia.20453

216. Norris JG, Tang LP, Sparacio SM, Benveniste EN. Signal transduction pathways mediating astrocyte IL- 6 induction by IL- 1 beta and tumor necrosis factor-alpha. J Immunol. (1994) 152:841-50.

217. Paco S, Hummel M, Plá V, Sumoy L, Aguado F. Cyclic AMP signaling restricts activation and promotes maturation and antioxidant defenses in astrocytes. BMC Genomics. (2016) 17:1-11. doi: 10.1186/s12864-016-2623-4

218. Vardjan N, Kreft M, Zorec R. Dynamics of $\beta$-adrenergic/cAMP signaling and morphological changes in cultured astrocytes. Glia. (2014) 62:56679. doi: $10.1002 /$ glia. 22626

219. Andersson AK, Rönnbäck L, Hansson E. Lactate induces tumour necrosis factor- $\alpha$, interleukin- 6 and interleukin- $1 \beta$ release in microglialand astroglial-enriched primary cultures. J Neurochem. (2005) 93:132733. doi: 10.1111/j.1471-4159.2005.03132.x

220. Rahman MH, Bhusal A, Kim JH, Jha MK, Song GJ, Go Y, et al. Astrocytic pyruvate dehydrogenase kinase-2 is involved in hypothalamic inflammation in mouse models of diabetes. Nat Commun. (2020) 11:5906. doi: 10.1038/s41467-020-19576-1

221. Kolobova E, Tuganova A, Boulatnikov I, Popov KM. Regulation of pyruvate dehydrogenase activity through phosphorylation at multiple sites. Biochem J. (2001) 358:69-77. doi: 10.1042/bj3580069

222. Xu J, Zheng Y, Lv S, Kang J, Yu Y, Hou K, et al. Lactate promotes reactive astrogliosis and confers axon guidance potential to astrocytes under oxygen-glucose deprivation. Neuroscience. (2020) 442:54-68. doi: 10.1016/j.neuroscience.2020.0 6.041

223. Herrmann JE, Imura T, Song B, Qi J, Ao Y, Nguyen TK, et al. STAT3 is a critical regulator of astrogliosis and scar formation after spinal cord injury. J Neurosci. (2008) 28:7231-43. doi: 10.1523/JNEUROSCI.1709-08. 2008

224. Bingul D, Kalra K, Murata EM, Belser A, Dash MB. Persistent changes in extracellular lactate dynamics following synaptic potentiation. Neurobiol Learn Mem. (2020) 175:107314. doi: 10.1016/j.nlm.2020.10 7314

Conflict of Interest: The authors declare that the research was conducted in the absence of any commercial or financial relationships that could be construed as a potential conflict of interest.

Copyright (C) 2021 Tang, Bair and Descalzi. This is an open-access article distributed under the terms of the Creative Commons Attribution License (CC BY). The use, distribution or reproduction in other forums is permitted, provided the original author(s) and the copyright owner(s) are credited and that the original publication in this journal is cited, in accordance with accepted academic practice. No use, distribution or reproduction is permitted which does not comply with these terms. 